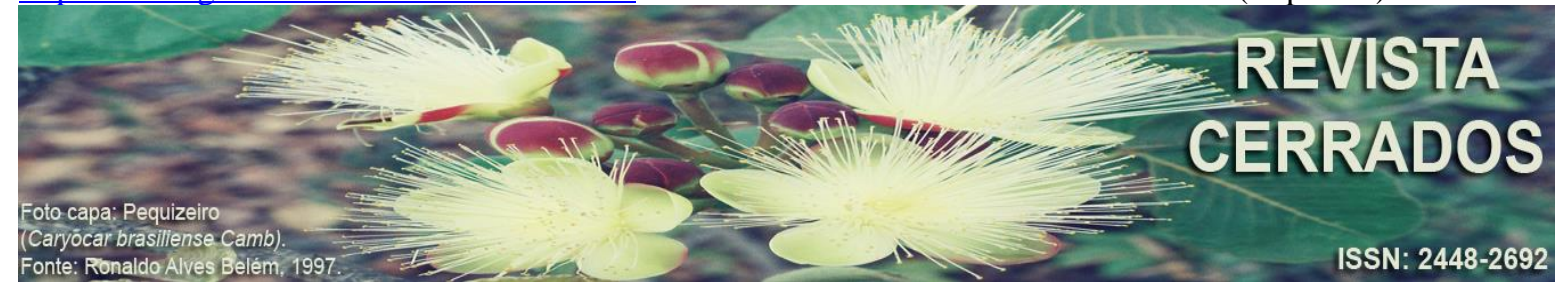

\title{
ATRIBUTOS QUÍMICOS E METAIS PESADOS EM SOLOS DE REMANESCENTES FLORESTAIS URBANOS
}

\section{CHEMICAL ATTRIBUTES AND HEAVY METALS IN SOILS OF URBAN FOREST REMAININGS}

\section{ATRIBUTOS QUÍMICOS Y METALES PESADOS EN SUELOS DE REMANENTES FORESTALES URBANOS}

\author{
Regina Márcia Longo \\ Pontifícia Universidade Católica de Campinas - PUC/Campinas, Campinas, São Paulo, Brasil \\ E-mail: <regina.longo@puc-campinas.edu.br>.
}

Pontifícia Universidade Católica de Campinas - PUC/Campinas, Campinas, São Paulo, Brasil

Denise Helena Lombardo Ferreira
E-mail: <lombardo@ @uc-campinas.edu.br>.

\begin{abstract}
Alessandra Leite da Silva
Universidade Estadual Paulista "Júlio de Mesquita Filho" - UNESP, Sorocaba,

São Paulo, Brasil

E-mail: 〈alessandra.leite@unesp.br〉.

Júlio César Penereiro 10

Observatório Municipal de Campinas Jean Nicolini, Campinas, São Paulo, Brasil

E-mail: <jcpenereiro@yahoo.com.br>.
\end{abstract}

\section{Deborah Regina Mendes}

Pontifícia Universidade Católica de Campinas - PUC/Campinas, Campinas, São Paulo, Brasil

E-mail: <deborahmendes56@gmail.com>.

\section{RESUMO}

Apesar de legislações que promovem a proteção de determinadas áreas relevantes, como as unidades de conservação, a borda destas encontra-se altamente sujeita aos efeitos externos, conhecido como efeito de borda. Este fenômeno se manifesta pela alteração das características da vegetação, da fauna e do solo nesta área. Diante disso, o objetivo deste trabalho foi quantificar aspectos da fertilidade do solo e dos metais pesados: chumbo $(\mathrm{Pb})$, cromo $(\mathrm{Cr})$ e níquel (Ni) que possam estar presentes no solo nas bordas da Mata de Santa Genebra, 
LONGO, R. M.; FERREIRA, D. H. L.; SILVA, A. L.; PENEREIRO, J. C.; MENDES, D. R.

Atributos químicos e metais pesados em solos de remanescentes florestais urbanos

Campinas/SP, Brasil, a fim de verificar a interferência dos diferentes graus de uso e ocupação do entorno. Realizaram-se coletas de amostras de solo em 40 pontos da borda do fragmento, equidistantes em $200 \mathrm{~m}$, e procederam-se análises químicas de fertilidade e de metais pesados. Nas amostras foram determinados os teores de: $\mathrm{pH}\left(\mathrm{CaCl}_{2}\right)$; matéria orgânica $(\mathrm{MO})$; fósforo $(\mathrm{P})$, potássio $(\mathrm{K})$, cálcio $(\mathrm{Ca})$ e magnésio $(\mathrm{Mg})$. Os valores da capacidade de troca de cátions (T) e da saturação por bases (V\%) foram obtidos por meio de cálculos. Nas leituras das amostras para a determinação quantitativa dos metais: chumbo $(\mathrm{Pb})$, cromo $(\mathrm{Cr})$ e níquel (Ni) foi utilizada a Espectrofotometria de Absorção Atômica (EAA) por atomização em chama. Após análise dos resultados obtidos pode-se observar que o remanescente em estudo apresenta condições de conservação em relação à fertilidade natural do solo que pode vir a auxiliar nos programas de reflorestamento. No entanto, algumas regiões do entorno, principalmente aquelas que se encontram sob pressões externas (urbanização, presença de estradas e atividades rurais), apresentaram alterações nos teores de metais pesados em estudo.

Palavras-chave: Metais pesados. Conservação de áreas naturais. Solo florestal. Áreas verdes. Remanescentes florestais urbanos.

\begin{abstract}
Despite legislation that promotes the protection of certain relevant areas, such as conservation units, their edges are highly subject to external effects, known as the edge effect. This phenomenon is manifested by the alteration of the characteristics of vegetation, fauna and soil in this area. Therefore, the objective of this work was to quantify aspects of soil fertility and heavy metals: lead $(\mathrm{Pb})$, chromium $(\mathrm{Cr})$ and nickel $(\mathrm{Ni})$ that may be present in the soil at the edges of the Forest of Santa Genebra, Campinas/SP, Brazil, in order to verify the interference of the different degrees of use and occupation of the surroundings. Soil samples were collected at 40 points on the edge of the fragment, equidistant in $200 \mathrm{~m}$, and chemical analyzes of fertility and heavy metals were carried out. In the samples, the contents of: $\mathrm{pH}$ $(\mathrm{CaCl} 2)$; organic matter $(\mathrm{OM})$; phosphorus $(\mathrm{P})$, potassium $(\mathrm{K})$, calcium $(\mathrm{Ca})$ and magnesium $(\mathrm{Mg})$. The values of the cation exchange capacity $(\mathrm{T})$ and base saturation (V\%) were obtained through calculations. In the readings of the samples for the quantitative determination of the metals: lead $(\mathrm{Pb})$, chromium $(\mathrm{Cr})$ and nickel $(\mathrm{Ni})$, Atomic Absorption Spectrophotometry (SAA) by flame atomization was used. After analyzing the results obtained, it can be seen that the remainder under study has conservation conditions in relation to the natural fertility of the soil that may come to assist in reforestation programs. However, some regions of the surrounding, mainly those that are under external pressure (urbanization, presence of roads and rural activities), presented changes in the levels of heavy metals under study.
\end{abstract}

Keywords: Heavy metals. Conservation of natural areas. Forest soil. Green areas. Urban forest remainings.

\title{
RESUMEN
}

A pesar de la legislación que promueve la protección de ciertas áreas relevantes, como las unidades de conservación, su borde está altamente sujeto a efectos externos, conocidos como el efecto borde. Este fenómeno se manifiesta por la alteración de las características de la vegetación, la fauna y el suelo en esta área. Por lo tanto, el objetivo de este trabajo fue cuantificar aspectos de la fertilidad del suelo y metales pesados: plomo $(\mathrm{Pb})$, cromo $(\mathrm{Cr})$ y 
LONGO, R. M.; FERREIRA, D. H. L.; SILVA, A. L.; PENEREIRO, J. C.; MENDES, D. R. Atributos químicos e metais pesados em solos de remanescentes florestais urbanos

níquel (Ni) que pueden estar presentes en el suelo en los bordes del bosque de Santa Genebra, Campinas/SP, Brasil, para verificar la interferencia de los diferentes grados de uso y ocupación de los alrededores. Se recogieron muestras de suelo en 40 puntos en el borde del fragmento, equidistantes en $200 \mathrm{~m}$, y se llevaron a cabo análisis químicos de fertilidad y metales pesados. En las muestras, el contenido de: $\mathrm{pH}(\mathrm{CaCl})$; materia orgánica $(\mathrm{OM})$; fósforo $(\mathrm{P})$, potasio $(\mathrm{K})$, calcio $(\mathrm{Ca})$ y magnesio $(\mathrm{Mg})$. Los valores de la capacidad de intercambio catiónico $(\mathrm{T})$ y la saturación de bases $(\mathrm{V} \%)$ se obtuvieron mediante cálculos. En las lecturas de las muestras para la determinación cuantitativa de los metales: plomo $(\mathrm{Pb})$, cromo (Cr) y níquel (Ni), se utilizó Espectrofotometría de Absorción Atómica (EAA) por atomización a llama. Después de analizar los resultados obtenidos, se puede ver que el remanente en estudio presenta condiciones de conservación en relación con la fertilidad natural del suelo que puede ayudar a los programas de reforestación. Sin embargo, algunas regiones del circundante, principalmente aquellas que están bajo presión externa (urbanización, presencia de carreteras y actividades rurales), presentaron cambios en los niveles de los metales pesados en estudio.

Palabras clave: Metales pesados. Conservación de espacios naturales. Suelo forestal. Áreas verdes. Remanentes forestales urbanos.

\section{INTRODUÇÃO}

O solo é um componente essencial em processos de recuperação de áreas degradadas por se tratar, de um modo geral, da base de implantação de processos que podem culminar na restauração de funções ecológicas do ecossistema como um todo. Esses processos são complexos e dependem, principalmente do entendimento de como se deu o processo de degradação e também de indicadores que quantifiquem o nível de degradação que o ambiente se encontra (LONGO et al., 2013; LONGO et al., 2015). A partir do início das atividades industriais ocorre um aumento nos processos de contaminação ambiental estando os solos como um dos recursos naturais que mais sofreram esse impacto. A crescente exploração de recursos naturais e descarte de resíduos, especialmente nos solos, promoveu diversos impactos, superando em muitas regiões, a resiliência do ambiente natural (BIONDI, 2010).

Com a intervenção do ser humano no meio ambiente é possível observar a degradação dos recursos naturais e o aparecimento de fatores ambientais de risco (SOUSA, 2014). Neste sentido, destaca-se a importância da interação entre especialistas em diversas áreas, a fim de se estudar os prejuízos ao meio ambiente, mas também considerando os efeitos na saúde animal e humana (ARAÚJO et al., 2017).

Assim, estudos sobre as características químicas de solos em remanescentes florestais imersos em áreas urbanas tornam-se fundamentais, por serem áreas vegetadas, 
LONGO, R. M.; FERREIRA, D. H. L.; SILVA, A. L.; PENEREIRO, J. C.; MENDES, D. R. Atributos químicos e metais pesados em solos de remanescentes florestais urbanos

interrompidas por elementos naturais (lagos, rios, entre outros) ou antrópicos (estradas, culturas agrícolas, entre outros) que sofrem ações em suas áreas de borda capazes de alterar a dinâmica do local, de modo a impossibilitar o retorno dessas áreas ao estágio antes da degradação.

A fragilidade dos remanescentes florestais urbanos está ligada também ao tamanho da borda e do fragmento em estudo (ETTO et al., 2013; FENGLER et al., 2015). De acordo com Fengler et. al. (2015), o fator da forma expressa a vulnerabilidade deste às perturbações oriundas do efeito de borda. Este indicador é calculado pela relação entre área da região florestal em análise e o seu perímetro, classificando os fragmentos em arredondados, alongados e muito alongados (GREGGIO et al., 2009). Diferentemente de fragmentos arredondados e, portanto, mais compacto, nos mais alongados sua região central se apresenta mais próxima à borda, provocando maior interferência dos efeitos do uso e a ocupação no entorno. Silva et al. (2015) destacam ainda que fragmentos com área inferior a 1 ha apresentam uma alta proporção entre perímetro de borda e área e são, portanto, os mais susceptíveis a essas interferências externas.

Neste aspecto, a vegetação localizada na borda está mais exposta a distúrbios e variações microclimáticas comparadas àquelas do interior, alterando assim as características físicas, químicas e biológicas, contribuindo para a degradação do solo, entre outros problemas ambientais, tais como: baixa taxa de infiltração de água; aumento da temperatura; erosão acentuada; aumento de espécies invasoras que interferem no desenvolvimento das espécies nativas prejudicando a longevidade do fragmento, dentre outros (OLIVEIRA et al., 2015; ETTO et al., 2013; SANTOS et al., 2018; SANTOS et al., 2013).

Dentre os indicadores de degradação de solo pode-se destacar os níveis tóxicos de metais que são comuns, devido a sua persistência por longos períodos e por se tratarem de elementos bioacumulativos em seres vivos, biodegradáveis, de distintos estados de oxidação, de mobilidade variada, de biodisponibilidade e alta toxidade, representando uma ameaça potencial à biodiversidade e aos ecossistemas (FERREIRA, 2015; FERREIRA; HORTA, 2010; ABREU et al., 2002). Segundo os "Valores de Referência de Qualidade" para solo (CETESB, 2005)

Os metais pesados (MP) são encontrados naturalmente na natureza, sendo classificados de acordo com a sua densidade relativa (MP > 5g.cm ${ }^{-3}$ ); nos solos, são provenientes originalmente de rochas além de outras fontes como: precipitação atmosférica, 
LONGO, R. M.; FERREIRA, D. H. L.; SILVA, A. L.; PENEREIRO, J. C.; MENDES, D. R. Atributos químicos e metais pesados em solos de remanescentes florestais urbanos

cinzas, calcário, fertilizantes químicos e adubos orgânicos. Os principais elementos químicos enquadrados neste conceito são: alumínio, cádmio, chumbo, cobre, cobalto, cromo, ferro, manganês, mercúrio e zinco (ALEXANDRE et al., 2012, TSUTIYA, 2015). Alguns desses são essenciais à manutenção da vida no planeta pois desempenharem funções biológicas importantes no metabolismo de diversos organismos. Podem atuar como cofatores enzimáticos em mamíferos, plantas e microrganismos como o Ferro (Fe), o Zinco (Zn), o Cobre $(\mathrm{Cu})$, o Níquel (Ni) e o Manganês (Mn). O Crômio (Cr), desde que em teores baixos é essencial, especialmente aos mamíferos, contribuindo no metabolismo da glicose. Cabe destacar que, em teores altos, mesmo os essenciais podem causar toxicidade, podendo apresentar ação carcinogênica e efeitos deletérios a diversos organismos vivos, incluindo o homem (BIONDI, 2010).

A contaminação no solo por esses elementos pode ser natural, devido aos processos pedogênicos no material de origem, pelos agentes do intemperismo (destaque hídrico) ou de forma antrópica por resíduos oriundos de atividades minerais, fundição, produção e reciclagem de baterias, produtos químicos utilizados na agricultura e na indústria, processos de incineração e emissões veiculares, sendo essa fonte a principal razão do aumento de contaminação do solo na atualidade (ABREU et al., 2002).

Diante destas perspectivas, o presente trabalho teve como objetivo quantificar o teor de metais pesados e a concentração de alguns macros e micronutrientes em áreas de bordas da Mata de Santa Genebra, importante remanescente florestal de Mata Atlântica localizado em Campinas-SP. Presume-se que os resultados dessas análises possam fornecer importantes informações adicionais das condições do citado local de interesse e, ao mesmo tempo, possibilitam auxiliar os gestores de restauração e manejo florestal, além de permitirem averiguar o cenário atual sobre o comportamento do meio ambiente e das possíveis pressões sofridas pelas ocupações das áreas do seu entorno.

\section{MATERIAL E MÉTODOS}

Classificada como Área de Relevante Interesse Ecológico (ARIE), a Mata de Santa Genebra é o maior fragmento de vegetação nativa do município de Campinas/SP, imersa em uma região exposta às pressões antrópicas, estando localizada ao sudoeste do distrito de Barão Geraldo, conforme mostra a Figura 1. 
LONGO, R. M.; FERREIRA, D. H. L.; SILVA, A. L.; PENEREIRO, J. C.; MENDES, D. R.

Atributos químicos e metais pesados em solos de remanescentes florestais urbanos

Figura 1: Localização da área de estudo

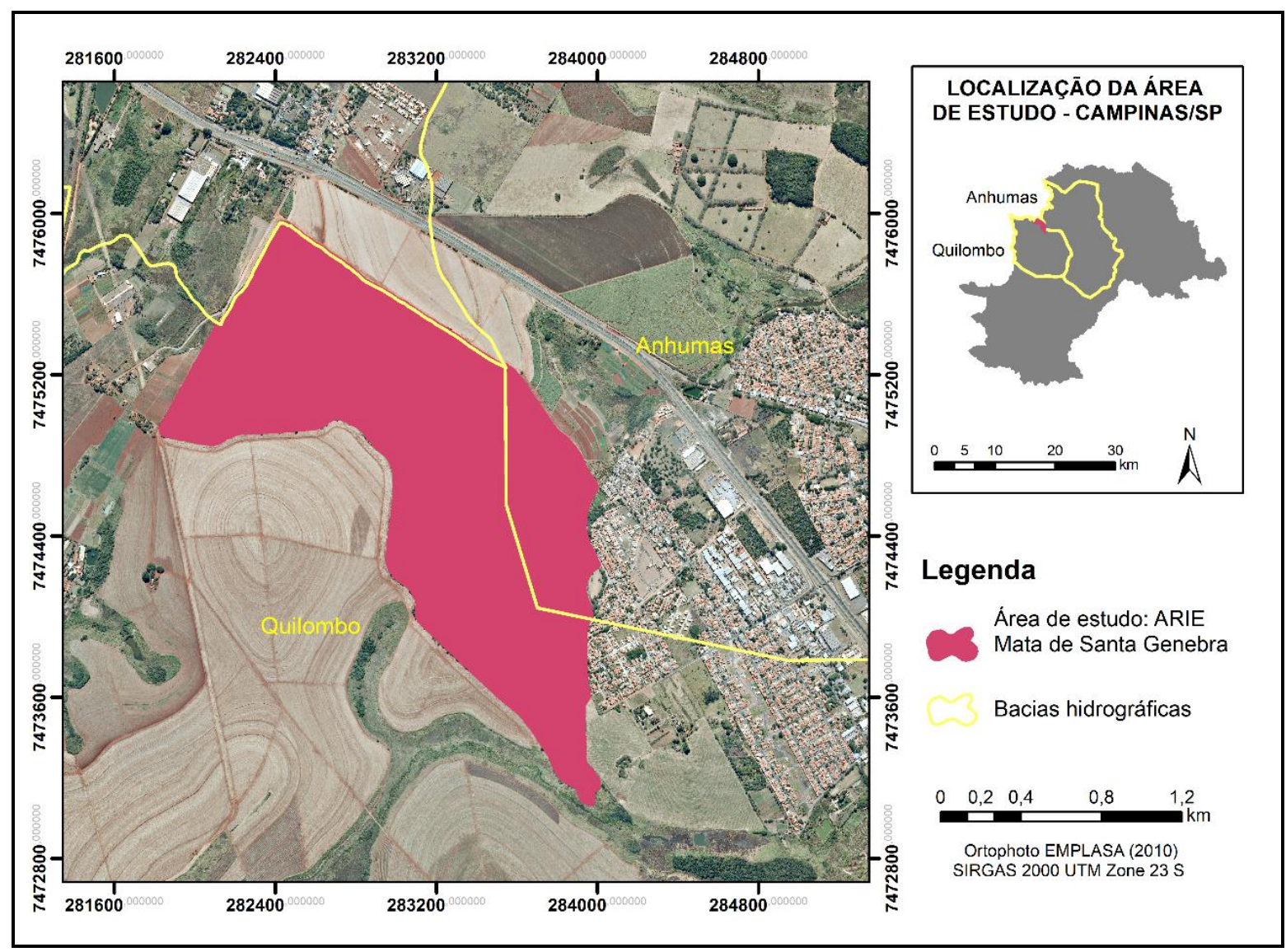

Fonte: Google Map (2019).

A área de estudo está inserida nas Bacias Hidrográficas Ribeirão Anhumas (sub bacia do Ribeirão das Pedras) e Ribeirão do Quilombo, possuindo uma área de 251,7 ha, 9 km de perímetro, sendo caracterizado como uma Floresta Estacional Semidecidual, com solo predominantemente do tipo Latossolo Vermelho-Escuro, com inserções que não se distinguem de solos hidromórficos (“Glei”). É coberta por uma floresta mesófila semidecídua estando assentada sobre relevo levemente ondulado com três regiões mais baixas e úmidas e duas discretas elevações, sendo que nas baixadas a floresta semidecídua é substituída pelas florestas higrófilas. No interior são observadas clareiras de idades e de alturas variadas, oriundas do corte raso para aproveitamento de lenha e da extração seletiva de madeira nobres em alguns trechos restritos (MORELLATO; LEITÃO FILHO, 1995).

O clima da região é quente úmido, com inverno seco e verão quente e chuvoso, apresentando uma temperatura média no mês mais quente é superior à $22^{\circ} \mathrm{C}$ e a do mês mais frio, inferior a $18^{\circ} \mathrm{C}$ (VELOSO; RANGEL FILHO; LIMA, 1991). Está cercada por uma 
LONGO, R. M.; FERREIRA, D. H. L.; SILVA, A. L.; PENEREIRO, J. C.; MENDES, D. R. Atributos químicos e metais pesados em solos de remanescentes florestais urbanos

matriz inóspita, visto que a maioria dos seus organismos e suas partes adjacentes estão propensas a uma variedade de modificações físicas e bióticas, relacionadas ao processo denominado efeito de borda, sendo que os principais usos e ocupação do entorno está associada a ocupação urbana (bairro residencial) e uso agrícola, principalmente cana-deaçúcar (GARCIA et al., 2018).

As amostras de solos foram coletadas nas áreas de borda em 40 pontos equidistantes em $200 \mathrm{~m}$ (Figura 2) numerados de 1 a 40. Em cada ponto de amostragem foi realizada a limpeza na área com auxílio de uma pá retirando serapilheira e outros detritos. Em seguida, com auxílio de um trado tipo holandês, foram retiradas 4 amostras simples na camada superficial $(0-20 \mathrm{~cm})$ que posteriormente foram misturadas em um balde (amostra composta) sendo em seguida armazenadas em sacos plásticos, identificadas conforme disposição dos pontos de monitoramento e encaminhadas ao laboratório onde foram secas e peneiradas em equipamentos de $2,0 \mathrm{~cm}$ de malha (TFSA - terra fina ao ar), conforme descrito em Santos et al. (2005). Posteriormente as amostras referentes a análise de fertilidade foram encaminhadas e analisadas em laboratório de solo e as análises de metais pesados foram realizadas no laboratório de química da PUC-Campinas

Ao todo foram constituídas dez bordas (B1 a B10) com diferentes interfaces com a matriz antrópica do entorno, cada uma delas possuindo quatro pontos de repetições (Figura 2).

As amostras foram encaminhas a um laboratório para fins de análise de fertilidade de rotina sendo realizadas as seguintes análises com a descrição do método apresentada de forma reduzida: os teores de: $\mathrm{pH}\left(\mathrm{CaCl}_{2}\right)$; matéria orgânica (MO) por oxidação pelo $\mathrm{H}_{2} \mathrm{SO}_{4} \mathrm{e}$ por quantificação colorimétrica; fósforo $(\mathrm{P})$, potássio $(\mathrm{K})$, cálcio $(\mathrm{Ca})$ e magnésio $(\mathrm{Mg})$, disponíveis e extraídos pela resina de troca iônica, sendo o elemento químico P quantificado por colorimetria. Os teores de potássio $(\mathrm{K})$, cálcio $(\mathrm{Ca})$ e magnésio $(\mathrm{Mg})$ foram determinados por espectrofotometria de absorção atômica; enquanto que para o alumínio (Al) extraído pelo $\mathrm{KCl}$ foi determinado por meio de titulação ácido-base. Os valores da capacidade de troca de cátions (T) e da saturação por bases (V\%) foram obtidos por meio de cálculos. Maiores detalhes dos métodos analíticos empregados no presente estudo podem ser conferidos em Raij et al. (1987). 
LONGO, R. M.; FERREIRA, D. H. L.; SILVA, A. L.; PENEREIRO, J. C.; MENDES, D. R.

Atributos químicos e metais pesados em solos de remanescentes florestais urbanos

Figura 2: Localização dos pontos de amostragem da área de estudo

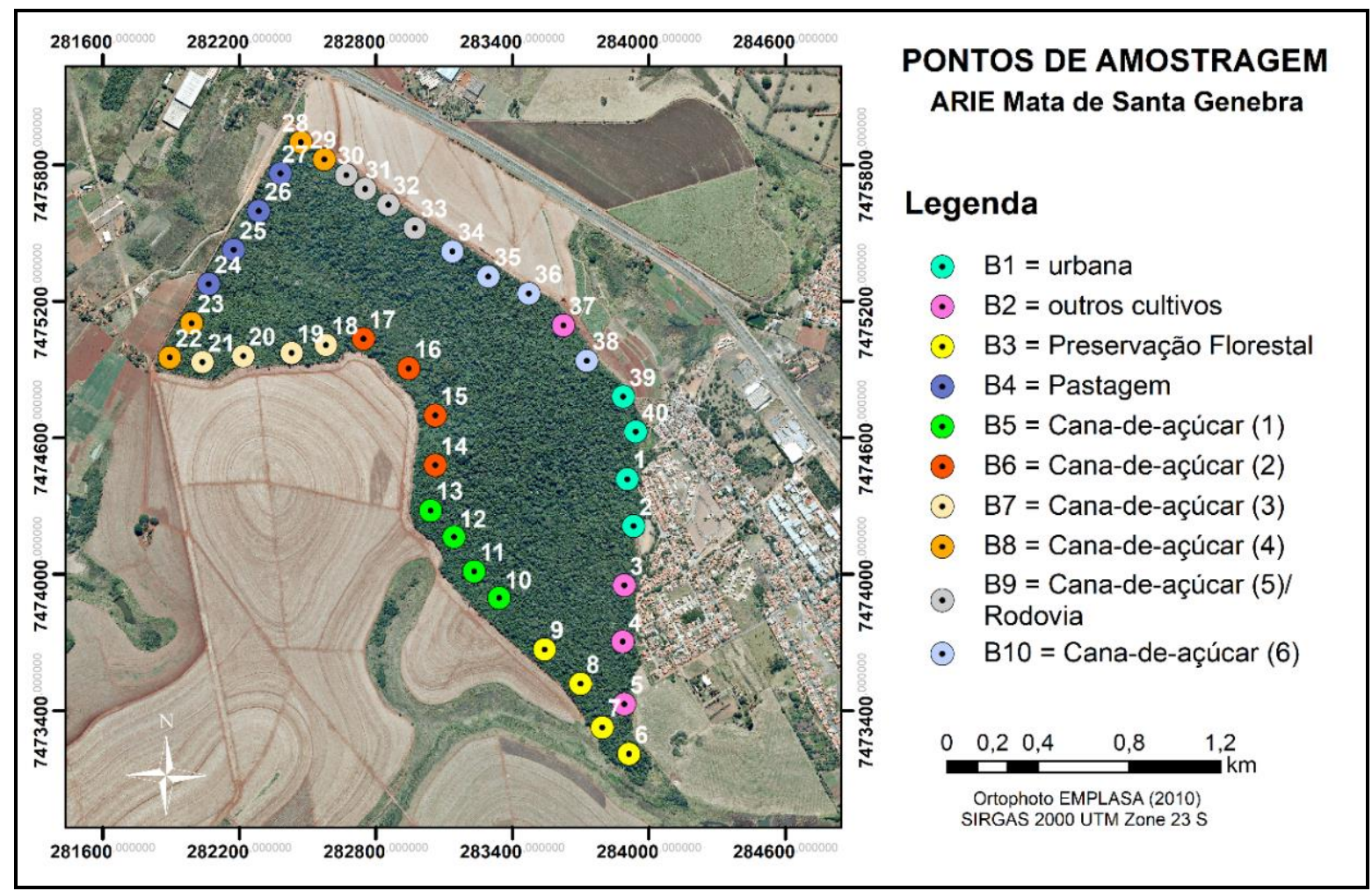

Fonte: Google Map (2019).

As principais interferências de borda estão ilustradas na Figura 3.

Figura 3: Principais interferências antrópicas nas áreas de bora da Mata de Santa

Genebra: uso agrícola e urbano

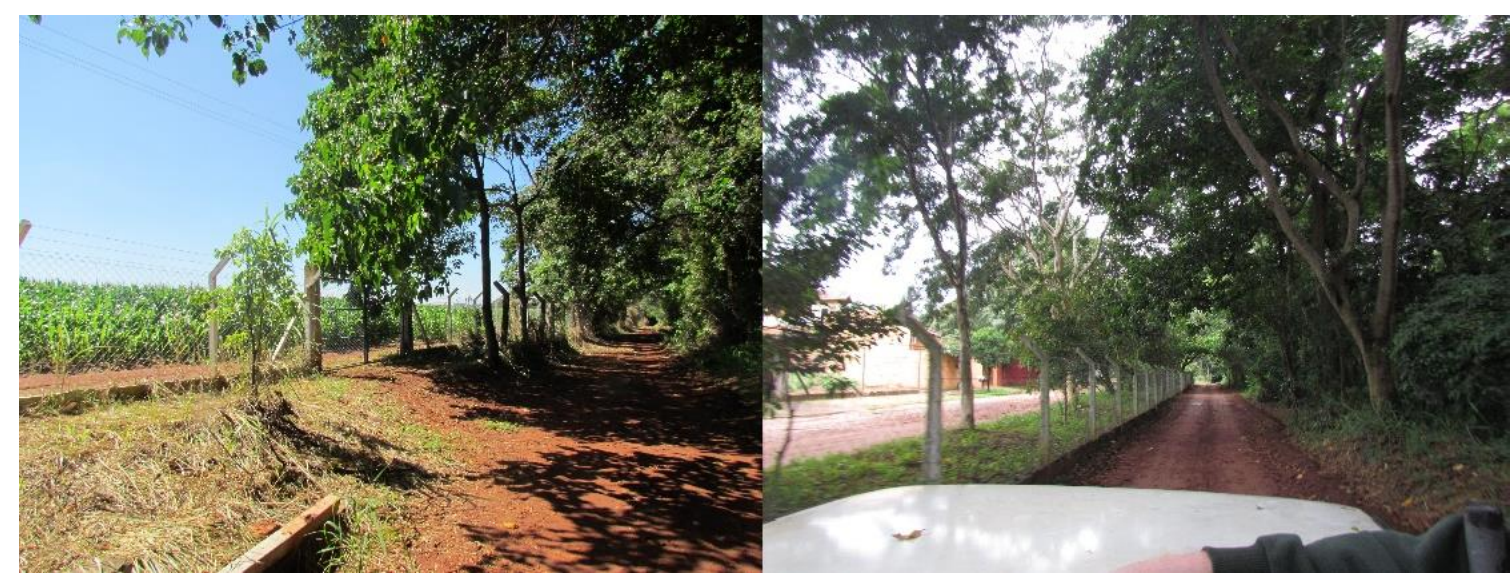

Fonte: Autores (2020).

A digestão das amostras de solo para a determinação dos metais pesados foi realizada seguindo o Método USEPA-3050B, (USEPA, 1996). Nas leituras das amostras para 
LONGO, R. M.; FERREIRA, D. H. L.; SILVA, A. L.; PENEREIRO, J. C.; MENDES, D. R.

Atributos químicos e metais pesados em solos de remanescentes florestais urbanos

a determinação quantitativa dos metais: chumbo $(\mathrm{Pb})$, cromo $(\mathrm{Cr})$ e níquel $(\mathrm{Ni})$ foi utilizada a Espectrofotometria de Absorção Atômica (EAA) por atomização em chama.

No presente estudo, o grau de poluição do solo para cada metal foi medido pelo índice de carga de poluição (pollution load index - PLI), dependendo das concentrações de metal do solo. A seguir, a Equação 1 foi utilizada para avaliar o nível de PLI nos solos conforme Liu et al. (2005):

$$
P L I=\frac{C \text { (solo })}{C(\text { referêneia })}
$$

Onde: $C$ (solo) e $C$ (referência) representam as concentrações de metais pesados nos solos e de referência, respectivamente.

Os resultados obtidos para todos os parâmetros relacionados aos macros e micronutrientes e aos metais pesados foram organizados e tratados por meio de planilhas do aplicativo Assistat (versão: 7.7 beta) (SILVA; AZEVEDO, 2016), o que possibilitou a realização de diferentes cálculos visando analisar a normalidade dos dados e tratamentos estatísticos, por meio da estatística descritiva e pela análise de componentes principais (ACP), com grau de probabilidade em 5\%. As correções, análises e gerações de gráficos foram realizadas por meio do aplicativo Microsoft Office Excel (versão: 2013).

\section{RESULTADOS E DISCUSSÃO}

Os resultados obtidos para os atributos químicos do solo, expressos na Tabela 1, foram comparados com os níveis de fertilidade adotados por Raij et al. (1987). De maneira geral pode-se observar que os valores de $\mathrm{pH}$ variaram de 4,6 a 6,1, sendo que aqueles solos próximos aos cultivos de cana-de-açúcar (B9) foram os que apresentaram maior acidez e via de regra, os valores ficaram próximos a 5,0 em todas as bordas. Desempenhos semelhantes foram observados para a saturação por bases, sendo que os locais que apresentaram os menores valores, também apresentaram os teores baixos de $\mathrm{Ca}^{2+}$ e elevada acidez potencial.

Comumente, os solos de floresta em ambientes tropicais apresentam maior acidez, quando comparados a solos sob cultivos tradicionais nas mesmas condições (YADA et al., 2015; LONGO et al., 2013); até mesmo em solos nos quais há cultivo orgânico (sob mata) é 
LONGO, R. M.; FERREIRA, D. H. L.; SILVA, A. L.; PENEREIRO, J. C.; MENDES, D. R.

Atributos químicos e metais pesados em solos de remanescentes florestais urbanos

possível identificar maior acidez quando comparados à solos sob cultivos tradicionais (SILVA, 2015). São mostrados na referida tabela o valor mínimo-máximo (dados superiores) e a média (desvio-padrão) (dados inferiores) calculados para cada borda dos atributos químicos analisados.

Tabela 1: Estatística descritiva dos atributos químicos nas amostras de solo coletadas na Mata de Santa Genebra

\begin{tabular}{|c|c|c|c|c|c|c|}
\hline & $\begin{array}{c}\text { P resina } \\
\left(\mathbf{m g . d m}^{-3}\right)\end{array}$ & $\begin{array}{c}\text { MO } \\
\left(\text { g.dm- }{ }^{3}\right)\end{array}$ & $\begin{array}{c}\mathrm{pH} \\
\left(\mathrm{Ca} \mathrm{Cl}_{2}\right)\end{array}$ & $\begin{array}{c}\mathrm{K} \\
\left(\mathbf{m m o l c . d m}-{ }^{3}\right) \\
\end{array}$ & $\begin{array}{c}\text { Ca } \\
\left(\text { mmolc.dm }^{-3}\right) \\
\end{array}$ & $\begin{array}{c}\text { Mg } \\
\left(\text { mmolc.dm }^{-3}\right) \\
\end{array}$ \\
\hline & \multicolumn{6}{|c|}{$\begin{array}{l}\text { Valor mínimo - Valor máximo } \\
\text { Média (desvio padrão) }\end{array}$} \\
\hline B1 & $\begin{array}{c}6-10 \\
8,3(1,7)\end{array}$ & $\begin{array}{c}43-54 \\
48,5(5,8)\end{array}$ & $\begin{array}{c}5,4-5,9 \\
5,7(0,2)\end{array}$ & $\begin{array}{c}2,1-3,7 \\
2,8(0,8)\end{array}$ & $\begin{array}{c}40-86 \\
69,0(20,8)\end{array}$ & $\begin{array}{c}16-30 \\
21,0(6,4)\end{array}$ \\
\hline B2 & $\begin{array}{c}7-36 \\
15,3(13,9) \\
\end{array}$ & $\begin{array}{c}40-51 \\
47,3(5)\end{array}$ & $\begin{array}{c}4,8-5,7 \\
5,3(0,5)\end{array}$ & $\begin{array}{c}1,6-3,1 \\
2,1(0,7)\end{array}$ & $\begin{array}{c}27-104 \\
61,3(34,7) \\
\end{array}$ & $\begin{array}{c}9-25 \\
15,3(7,1)\end{array}$ \\
\hline B3 & $\begin{array}{c}9-17 \\
12,3(3,6)\end{array}$ & $\begin{array}{c}51-67 \\
56(7,6)\end{array}$ & $\begin{array}{c}5,2-5,6 \\
5,5(0,2)\end{array}$ & $\begin{array}{c}1,7-3,8 \\
2,8(1,1)\end{array}$ & $\begin{array}{c}36-86 \\
63,5(24,9)\end{array}$ & $\begin{array}{c}16-54 \\
29(17)\end{array}$ \\
\hline B4 & $\begin{array}{c}11-14 \\
12,5(1,3) \\
\end{array}$ & $\begin{array}{c}45-56 \\
50,5(4,5) \\
\end{array}$ & $\begin{array}{l}4,5-5,9 \\
5,1(0,6)\end{array}$ & $\begin{array}{c}1,9-3,4 \\
2,7(0,8)\end{array}$ & $\begin{array}{c}19-125 \\
62(44,7) \\
\end{array}$ & $\begin{array}{c}8-17 \\
14(4,1)\end{array}$ \\
\hline B5 & $\begin{array}{c}7-16 \\
12(3,7)\end{array}$ & $\begin{array}{c}34-63 \\
54(13,5)\end{array}$ & $\begin{array}{c}5-6,1 \\
5,7(0,5)\end{array}$ & $\begin{array}{l}1,6-6,3 \\
3,4(2)\end{array}$ & $\begin{array}{c}45-135 \\
89(39,6)\end{array}$ & $\begin{array}{c}17-30 \\
22,3(6,0)\end{array}$ \\
\hline B6 & $\begin{array}{c}8-14 \\
11,5(2,5)\end{array}$ & $\begin{array}{c}52-67 \\
60(7,6)\end{array}$ & $\begin{array}{c}5,9-6,3 \\
6,1(0,2)\end{array}$ & $\begin{array}{l}2,2-4,3 \\
3,3(1)\end{array}$ & $\begin{array}{c}93-128 \\
113(17,5)\end{array}$ & $\begin{array}{c}20-29 \\
24,5(4,7)\end{array}$ \\
\hline B7 & $\begin{array}{c}8-14 \\
11(2,4)\end{array}$ & $\begin{array}{c}36-64 \\
47,5(13,5)\end{array}$ & $\begin{array}{c}4,6-6,3 \\
5,5(0,9)\end{array}$ & $\begin{array}{c}1,6-3 \\
2,4(0,7)\end{array}$ & $\begin{array}{c}20-148 \\
69,5(61,5)\end{array}$ & $\begin{array}{c}6-47 \\
21,5(19,3)\end{array}$ \\
\hline B8 & $\begin{array}{c}12-19 \\
116,8(3,2)\end{array}$ & $\begin{array}{c}43-60 \\
52,5(7)\end{array}$ & $\begin{array}{c}4,9-5,7 \\
5,3(0,3)\end{array}$ & $\begin{array}{c}1,6-2,6 \\
2,1(0,4)\end{array}$ & $\begin{array}{c}30-100 \\
63(28,7)\end{array}$ & $\begin{array}{c}10-26 \\
17,5(6,6)\end{array}$ \\
\hline B9 & $\begin{array}{c}10-16 \\
12,8(2,5) \\
\end{array}$ & $\begin{array}{c}46-56 \\
52,5(4,5)\end{array}$ & $\begin{array}{l}4,2-5,7 \\
4,7(0,7)\end{array}$ & $\begin{array}{l}1,2-3,5 \\
2,1(1)\end{array}$ & $\begin{array}{c}15-60 \\
29,3(21)\end{array}$ & $\begin{array}{c}6-24 \\
11,8(8,5)\end{array}$ \\
\hline \multirow[t]{3}{*}{ B10 } & $\begin{array}{c}6-17 \\
11,5(4,7) \\
\end{array}$ & $\begin{array}{c}39-57 \\
45,8(7,9) \\
\end{array}$ & $\begin{array}{c}4-6,4 \\
4,8(1,1)\end{array}$ & $\begin{array}{c}0,9-2,2 \\
1,5(0,5)\end{array}$ & $\begin{array}{c}18-82 \\
40,3(29,5)\end{array}$ & $\begin{array}{c}6-23 \\
11,5(8)\end{array}$ \\
\hline & $\begin{array}{c}\mathrm{H}+\mathrm{Al} \\
\left(\mathrm{mmolc.dm}^{-3}\right) \\
\end{array}$ & $\begin{array}{c}\text { Al } \\
\left(\text { mmolc.dm }^{-3}\right) \\
\end{array}$ & $\begin{array}{c}\text { SB } \\
\left(\text { mmolc.dm }^{-3}\right) \\
\end{array}$ & $\begin{array}{c}\mathrm{S} \\
\left(\mathrm{mg.dm}^{-3}\right) \\
\end{array}$ & $\begin{array}{c}\text { B } \\
\left(\mathbf{m g . d m}^{-3}\right) \\
\end{array}$ & $\begin{array}{c}\mathrm{Cu} \\
\left(\mathbf{m g . d m}^{-3}\right)\end{array}$ \\
\hline & \multicolumn{6}{|c|}{$\begin{array}{l}\text { Valor mínimo - Valor máximo } \\
\text { Média (desvio padrão) }\end{array}$} \\
\hline B1 & $\begin{array}{c}19-35 \\
26,8(8,4)\end{array}$ & $\begin{array}{c}0-0 \\
0(0)\end{array}$ & $\begin{array}{l}60,4-114,5 \\
93,1(23,5)\end{array}$ & $\begin{array}{c}23-40 \\
30,5(8,3)\end{array}$ & $\begin{array}{c}0,6-1,6 \\
0,9(0,5)\end{array}$ & $\begin{array}{c}2,2-3,3 \\
2,6(0,5)\end{array}$ \\
\hline B2 & $\begin{array}{c}15-38 \\
26(9,4)\end{array}$ & $\begin{array}{c}0-3 \\
1,3(1,5)\end{array}$ & $\begin{array}{c}38-132,4 \\
78,9(42,3)\end{array}$ & $\begin{array}{c}18-40 \\
30(9,6)\end{array}$ & $\begin{array}{l}0,2-1,13 \\
0,6(0,4)\end{array}$ & $\begin{array}{c}2,5-6,4 \\
3,9(1,7)\end{array}$ \\
\hline B3 & $\begin{array}{c}28-55 \\
37(12,4)\end{array}$ & $\begin{array}{c}0-2 \\
0,5(1)\end{array}$ & $\begin{array}{l}55,8-144,2 \\
95,6(39,4)\end{array}$ & $\begin{array}{c}19-39 \\
30,8(9,2)\end{array}$ & $\begin{array}{c}0,24-1,21 \\
0,6(0,4)\end{array}$ & $\begin{array}{l}7,5-28,6 \\
14(9,8)\end{array}$ \\
\hline B4 & $\begin{array}{c}23-64 \\
41(16,9)\end{array}$ & $\begin{array}{c}0-6 \\
2,5(2,5)\end{array}$ & $\begin{array}{c}31-143,3 \\
77,9(46,9)\end{array}$ & $\begin{array}{c}26-38 \\
31,5(4,9)\end{array}$ & $\begin{array}{l}0,2-0,94 \\
0,4(0,4)\end{array}$ & $\begin{array}{c}6,6-8,6 \\
7,9(1,0)\end{array}$ \\
\hline B5 & $\begin{array}{c}12-27 \\
20,8(6,5)\end{array}$ & $\begin{array}{c}0-1 \\
0,3(0,5)\end{array}$ & $\begin{array}{r}65,4-162 \\
115(45) \\
\end{array}$ & $\begin{array}{c}17-38 \\
27(8,8)\end{array}$ & $\begin{array}{l}0,2-1,15 \\
0,7(0,5)\end{array}$ & $\begin{array}{l}4,8-8,8 \\
6,1(1,8)\end{array}$ \\
\hline B6 & $\begin{array}{c}16-22 \\
18,5(2,5)\end{array}$ & $\begin{array}{c}0-0 \\
0(0)\end{array}$ & $\begin{array}{l}118-160,6 \\
141(21,9) \\
\end{array}$ & $\begin{array}{c}17-33 \\
26,5(7,9)\end{array}$ & $\begin{array}{c}0,74-1,4 \\
1(0,3)\end{array}$ & $\begin{array}{c}3-5,8 \\
4,2(1,2)\end{array}$ \\
\hline B7 & $\begin{array}{c}19-43 \\
28,8(10,8)\end{array}$ & $\begin{array}{c}0-13 \\
5,3(6,4)\end{array}$ & $\begin{array}{l}29,1-198,4 \\
93,6(81,1) \\
\end{array}$ & $\begin{array}{c}25-38 \\
29,5(5,9)\end{array}$ & $\begin{array}{c}0,24-1,34 \\
0,7(0,5)\end{array}$ & $\begin{array}{c}2,9-3,9 \\
3,4(0,4)\end{array}$ \\
\hline B8 & $\begin{array}{c}19-48 \\
35(13,1) \\
\end{array}$ & $\begin{array}{c}0-3 \\
1,5(1,3)\end{array}$ & $\begin{array}{l}43-128,5 \\
83(35,1)\end{array}$ & $\begin{array}{c}27-47 \\
38,8(8,7) \\
\end{array}$ & $\begin{array}{c}0,36-0,96 \\
0,6(0,3)\end{array}$ & $\begin{array}{c}2,7-7,8 \\
4,9(2,1)\end{array}$ \\
\hline B9 & $\begin{array}{c}32-67 \\
52(14,7)\end{array}$ & $\begin{array}{c}0-17 \\
9,8(7,8)\end{array}$ & $\begin{array}{r}23,2-90,2 \\
44(31,5)\end{array}$ & $\begin{array}{c}22-49 \\
41,5(13)\end{array}$ & $\begin{array}{c}0,23-0,49 \\
0,4(0,1)\end{array}$ & $\begin{array}{l}3,5-33,8 \\
14(13,6)\end{array}$ \\
\hline B10 & $\begin{array}{c}13-82 \\
46,3(28,6)\end{array}$ & $\begin{array}{c}0-19 \\
11,3(8,1)\end{array}$ & $\begin{array}{c}25,2-107,5 \\
53,9(38)\end{array}$ & $\begin{array}{c}24-38 \\
32,8(6,1)\end{array}$ & $\begin{array}{c}0,23-0,83 \\
0,4(0,3)\end{array}$ & $\begin{array}{l}2,7-11,1 \\
6,1(4,0)\end{array}$ \\
\hline
\end{tabular}


LONGO, R. M.; FERREIRA, D. H. L.; SILVA, A. L.; PENEREIRO, J. C.; MENDES, D. R. Atributos químicos e metais pesados em solos de remanescentes florestais urbanos

\begin{tabular}{|c|c|c|c|c|c|c|}
\hline \multirow[t]{2}{*}{ Continuação } & $\begin{array}{c}\text { Fe } \\
\left(\mathrm{mg}^{-} \mathrm{dm}^{-3}\right)\end{array}$ & $\begin{array}{c}\text { Mn } \\
\left(\text { mg.dm }^{-3}\right)\end{array}$ & $\begin{array}{c}\text { Zn } \\
\left(\mathbf{m g . d m}^{-3}\right)\end{array}$ & $\begin{array}{c}\mathrm{Cr} \\
\left(\mathrm{mg.dm}^{-3}\right)\end{array}$ & $\begin{array}{c}\text { Pb } \\
\left(\mathbf{m g . d m}^{-3}\right)\end{array}$ & $\begin{array}{c}\mathrm{Ni} \\
\left(\mathrm{mg.dm}^{-3}\right)\end{array}$ \\
\hline & \multicolumn{6}{|c|}{$\begin{array}{l}\text { Valor mínimo - Valor máximo } \\
\text { Média (desvio padrão) }\end{array}$} \\
\hline B1 & $\begin{array}{c}11-52 \\
34,5(17,2)\end{array}$ & $\begin{array}{c}38-52 \\
47(6,2)\end{array}$ & $\begin{array}{c}3,3-8,2 \\
5,6(2,6)\end{array}$ & $\begin{array}{l}56,1-60,2 \\
58,4(1,8)\end{array}$ & $\begin{array}{c}42,7-170,2 \\
112,2(53,1)\end{array}$ & $\begin{array}{c}5,6-71,5 \\
41,8(27,8)\end{array}$ \\
\hline B2 & $\begin{array}{c}25-56 \\
39,5(16,8) \\
\end{array}$ & $\begin{array}{c}20,8-68 \\
35,5(22,3)\end{array}$ & $\begin{array}{l}3,5-10,2 \\
5,7(3,1)\end{array}$ & $\begin{array}{c}56,7-59,3 \\
58(1,1)\end{array}$ & $\begin{array}{c}75,4-133,9 \\
114,7(26,9) \\
\end{array}$ & $\begin{array}{l}23,7-61,9 \\
50,5(18)\end{array}$ \\
\hline B3 & $\begin{array}{c}26-96 \\
47,8(32,4)\end{array}$ & $\begin{array}{c}38-64 \\
50(11) \\
\end{array}$ & $\begin{array}{c}2,2-6,4 \\
4,1(1,9) \\
\end{array}$ & $\begin{array}{c}51,6-60,3 \\
57,5(4) \\
\end{array}$ & $\begin{array}{l}34,6-127,8 \\
73,7(39,7) \\
\end{array}$ & $\begin{array}{c}31,6-68,5 \\
50,3(18,9) \\
\end{array}$ \\
\hline B4 & $\begin{array}{c}22-52 \\
36(12,5)\end{array}$ & $\begin{array}{c}40-84 \\
60(19,9)\end{array}$ & $\begin{array}{c}2,1-7,8 \\
4,3(2,4)\end{array}$ & $\begin{array}{l}52-58,6 \\
55,7(3)\end{array}$ & $\begin{array}{l}39-120,1 \\
86(38,2)\end{array}$ & $\begin{array}{c}9,1-71 \\
48(29,3)\end{array}$ \\
\hline B5 & $\begin{array}{c}10-27 \\
15,3(7,9)\end{array}$ & $\begin{array}{c}28-114 \\
61(40,6)\end{array}$ & $\begin{array}{c}1,8-8,3 \\
4,9(2,8)\end{array}$ & $\begin{array}{l}51,3-57,8 \\
54,6(2,8)\end{array}$ & $\begin{array}{c}63-158,9 \\
104(43,4)\end{array}$ & $\begin{array}{r}40,8-83,5 \\
63(18,2) \\
\end{array}$ \\
\hline B6 & $\begin{array}{c}9-16 \\
12,8(2,9) \\
\end{array}$ & $\begin{array}{c}48-68 \\
60,5(8,7)\end{array}$ & $\begin{array}{c}3,3-7,1 \\
5,2(1,6)\end{array}$ & $\begin{array}{c}51,5-61 \\
56,4(4,1) \\
\end{array}$ & $\begin{array}{c}69-175,2 \\
102(49,4) \\
\end{array}$ & $\begin{array}{l}54,9-78,4 \\
64(10,3) \\
\end{array}$ \\
\hline B7 & $\begin{array}{c}14-104 \\
52,3(41,1)\end{array}$ & $\begin{array}{c}19,6-66 \\
48,9(21)\end{array}$ & $\begin{array}{c}2,5-6,8 \\
4,8(2,2) \\
\end{array}$ & $\begin{array}{l}45,5-59,7 \\
53,3(6,4) \\
\end{array}$ & $\begin{array}{l}46,9-114,3 \\
77,3(34,9) \\
\end{array}$ & $\begin{array}{c}16,7-56,8 \\
39,1(18,9) \\
\end{array}$ \\
\hline B8 & $\begin{array}{c}27-74 \\
46,8(20)\end{array}$ & $\begin{array}{c}36-104 \\
68(30,8)\end{array}$ & $\begin{array}{c}6,5-7,7 \\
6,9(0,5)\end{array}$ & $\begin{array}{l}54,4-57,2 \\
55,9(1,4)\end{array}$ & $\begin{array}{l}46-102,9 \\
81(25,5)\end{array}$ & $\begin{array}{l}23,3-79,2 \\
40,5(26)\end{array}$ \\
\hline B9 & $\begin{array}{c}27-230 \\
127(87,2)\end{array}$ & $\begin{array}{c}13,8-50 \\
34(18,1)\end{array}$ & $\begin{array}{c}2,9-3,9 \\
3,3(0,4)\end{array}$ & $\begin{array}{l}53,1-58,5 \\
56,3(2,4)\end{array}$ & $\begin{array}{l}98-111,9 \\
106(6,6)\end{array}$ & $\begin{array}{l}13,4-80,9 \\
47(31,9)\end{array}$ \\
\hline B10 & $\begin{array}{c}23-374 \\
180(151,9)\end{array}$ & $\begin{array}{c}2,4-38 \\
21,1(14,6)\end{array}$ & $\begin{array}{c}1,9-5 \\
3(1,4)\end{array}$ & $\begin{array}{l}53,8-58,9 \\
56,5(2,5)\end{array}$ & $\begin{array}{l}52,9-151,2 \\
104,8(43)\end{array}$ & $\begin{array}{c}20,5-58,4 \\
42,7(16,8)\end{array}$ \\
\hline
\end{tabular}

Observa-se que as concentrações de alguns elementos, tais como $\mathrm{Ca}, \mathrm{Al}, \mathrm{SB}, \mathrm{Cu}$ e Fe, demonstraram algumas variações nos diferentes trechos da borda, possivelmente devido aos diferentes usos do solo em áreas próximas às analisadas. Longo et al. (2013) observaram interferência direta do cultivo em áreas próximas das bordas em remanescentes florestais localizados em área urbana no município de Campinas. É o caso que se pode identificar para o $\mathrm{Ca}$, visto que os valores de cada borda apontados na Tabela 2, mostram-se em maiores concentrações nas bordas B5 e B6, que se referem àqueles locais com influência do plantio da cana-de-açúcar. Destaca-se que essas concentrações mais elevadas possam estar associadas ao uso de corretivos de $\mathrm{pH}$ do solo, onde predomina a utilização de calcário, além do uso de adubos superfosfatados que têm na sua formulação o Ca.

Em relação aos teores médios de MO, detectou-se que os valores estão entre 45,7 e 60,0 g.dm ${ }^{-3}$ (Tabela 2). Observa-se que a presença frequente de serapilheiras nos pontos de coleta são indícios da presença de MO, sendo esta de suma importância para o estabelecimento das vegetações arbóreas. Neste sentido, Longo et al. (2015) observaram variações nos teores de matéria orgânica em áreas de borda de remanescentes florestais de cerrado, provendo alterações diretas no banco de sementes e consequente interferência na regeneração natural desses ecossistemas. Para melhor avaliar os comportamentos de todos os parâmetros de fertilidade do solo, os mesmos estão retratados nos gráficos da Figura 4, em termos do logaritmo da substância química de interesse. 
LONGO, R. M.; FERREIRA, D. H. L.; SILVA, A. L.; PENEREIRO, J. C.; MENDES, D. R.

Atributos químicos e metais pesados em solos de remanescentes florestais urbanos

Figura 4: Comportamento da fertilidade do solo (em logaritmo) nas bordas da Mata de Santa Genebra

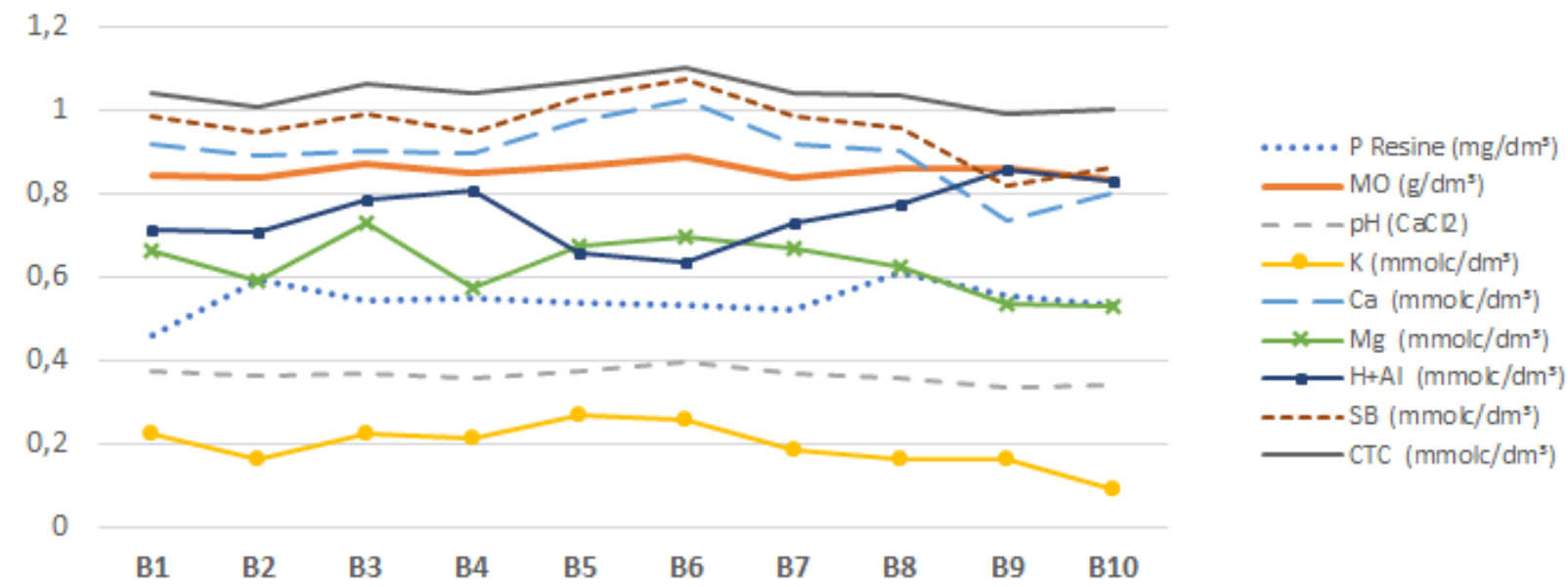

Nota: O eixo y não apresenta unidades por se tratar de uma escala logarítmica. Fonte: Autores (2020).

$\mathrm{Na}$ Figura 4, pode-se observar as variações que cada parâmetro possui de acordo com a borda avaliada, revelando ainda que o maior índice de fertilidade está associado à medida da CTC, seguida da SB, Ca e MO. Os demais parâmetros ( $\mathrm{H}+\mathrm{Al}, \mathrm{Mg}, \mathrm{P}_{\text {resina, }}$ pH e K) encontram-se praticamente num patamar inferior ao valor 30 e aos valores médios das bordas apresentando baixíssima concentração.

A Figura 5 apresenta o valor logarítmico para todos os micronutrientes e metais pesados avaliados nos dez segmentos de bordas da Mata de Santa Genebra, listados na Tabela 2. Uma análise dessa figura revela que o Fe foi o que acusou maiores irregularidades ao longo da borda, enquanto o $\mathrm{Pb}$ apresentou maiores índices para todas as bordas avaliadas. Os óxidos de ferro $(\mathrm{Fe})$ funcionam como indicadores importantes, especialmente em solos tropicais e subtropicais, os quais tendem a acumular, residualmente, óxidos e hidróxidos de ferro e alumínio (SOUZA JUNIOR et al., 2010). Os óxidos de ferro são considerados na literatura como indicadores pedoambientais; em pedoambientes aeróbios, estes minerais apresentam alta estabilidade e persistem no solo por longos períodos (INDA et al., 2014). Entretanto, em regiões tropicais nas quais ocorrem aumentos constantes, na umidade do solo, nos teores de matéria orgânica e, consequentemente, na atividade biológica há o favorecimento dos principais mecanismos de dissolução e remobilização dos óxidos de ferro no solo (INDA et al., 2013). 
LONGO, R. M.; FERREIRA, D. H. L.; SILVA, A. L.; PENEREIRO, J. C.; MENDES, D. R. Atributos químicos e metais pesados em solos de remanescentes florestais urbanos

Figura 5: Comportamento dos micronutrientes e metais pesados (em logaritmo) nas bordas da Mata de Santa Genebra

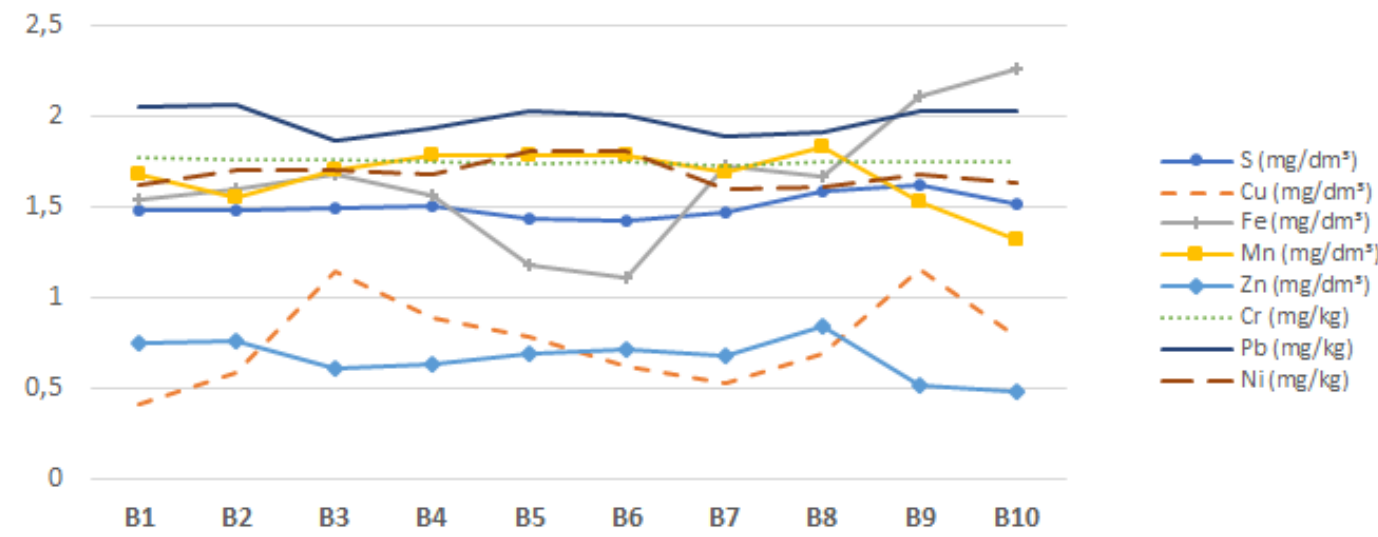

Nota: O eixo y não apresenta unidades por se tratar de uma escala logarítmica.

Fonte: Autores (2020).

No estudo da qualidade nutricional do solo, constatou-se um elevado teor de macronutrientes disponíveis evidenciados por teores altos de cobre $(\mathrm{Cu})$, zinco $(\mathrm{Zn})$, manganês $(\mathrm{Mn})$ e ferro $(\mathrm{Fe})$, tendo apenas o boro $(\mathrm{B})$ variado entre alto e médio devido a sua baixa disponibilidade no tipo de solo analisado. Fatores igualmente encontrados na análise dos micronutrientes que mesmo tendo baixa necessidade e interferência nutricional são de extrema importância para o adequado desenvolvimento da cobertura vegetal. Neste caso, observou-se predominância de $\mathrm{Ca}, \mathrm{Mg}$, enxofre $(\mathrm{S})$ e $\mathrm{P}$, com variação apenas em $\mathrm{K}$, elemento que atua diretamente nos valores de pH, saturação por base e CTC. A CTC demostrou que o solo em sua maioria possui adequada capacidade para reter os cátions necessários (RAIJ et al., 1987), exceto em $25 \%$ da área de borda, isto é, em pontos nos quais os teores dos elementos estão elevados e, principalmente o elemento $\mathrm{P}$, encontra-se em classificação muito alta o que evidencia a grande disponibilidade e a baixa absorção, esta situação observa-se predominante nos fragmentos de borda que confrontam a plantação de cana-de-açúcar.

As concentrações encontradas para os metais pesados foram comparadas também com os denominados "Limites de Intervenção", seguindo as diretrizes da ficha de informação toxicológica da CETESB (Decisão de Diretoria n ${ }^{\circ}$ 195-2005-E, de 23 de novembro de 2005). A Tabela 2 apresenta os resultados medidos para as análises químicas de solo para esses metais ( $\mathrm{Ni}, \mathrm{Pb}$ e $\mathrm{Cr}$ ) em cada ponto de coleta das amostras, além dos "Valores de Referência de Qualidade", sendo 13, 17 e 40, respectivamente (CETESB, 2005). Lembrando que esse é 
LONGO, R. M.; FERREIRA, D. H. L.; SILVA, A. L.; PENEREIRO, J. C.; MENDES, D. R.

Atributos químicos e metais pesados em solos de remanescentes florestais urbanos

um valor de referência relacionado à concentração de determinada substância no solo e, portanto, é um parâmetro que serve para definir se um solo tem altos índices de substâncias contaminantes ou não. Consequentemente, por meio dessas análises, detectou-se que a região da Mata de Santa Genebra vem sofrendo consideráveis contaminações, em particular pelo $\mathrm{Pb}$, impactando de forma preocupante aquela importante área de preservação ambiental do município de Campinas.

De maneira geral, foi possível identificar também que em seis bordas avaliadas a concentração de Ni ultrapassou os "Limites de Investigação Agrícola Apmáx" (70, 180 e 150, respectivamente). No entanto, em todos os pontos amostrados indicaram que os valores de $\mathrm{Cr}$ se mantiveram no "Limite de Prevenção" (30, 72 e 75, respectivamente), e houve variação quanto a concentração de $\mathrm{Pb}$. Isso é um fator que reforça a necessidade de controle e preservação daquele importante fragmento florestal (CETESB, 2005).

Tabela 2: Resultado das análises químicas de solo e "Valores de Referência de Qualidade"

\begin{tabular}{|c|c|c|c|c|}
\hline Pontos de coleta & Bordas & $\mathrm{Ni}\left(\mathrm{mg} . \mathrm{kg}^{-1}\right)$ & $\mathrm{Pb}\left(\mathrm{mg} . \mathrm{kg}^{-1}\right)$ & $\mathrm{Cr}\left(\mathrm{mg} . \mathrm{kg}^{-1}\right)$ \\
\hline 1 & B1 & 52,2 & 170,2 & 60,3 \\
\hline 2 & B1 & 71,5 & 107,6 & 59,3 \\
\hline 3 & B2 & 59,1 & 118,7 & 56,7 \\
\hline 4 & $\mathrm{~B} 2$ & 57,5 & 130,6 & 58,1 \\
\hline 5 & $\mathrm{~B} 2$ & 61,9 & 75,5 & 59,3 \\
\hline 6 & B3 & 68,5 & 127,8 & 58,3 \\
\hline 7 & B3 & 31,6 & 74,8 & 51,6 \\
\hline 8 & B3 & 36,7 & 34,6 & 60,3 \\
\hline 9 & B3 & 64,4 & 57,4 & 59,8 \\
\hline 10 & B5 & 69,9 & 39,4 & 58,6 \\
\hline 11 & B5 & 40,9 & 114,8 & 54,4 \\
\hline 12 & B5 & 71,0 & 120,1 & 57,8 \\
\hline 13 & B5 & 9,1 & 71,4 & 52,1 \\
\hline 14 & B6 & 69,9 & 63,3 & 51,4 \\
\hline 15 & B6 & 83,5 & 158,9 & 57,8 \\
\hline 16 & B6 & 40,8 & 76,4 & 53,4 \\
\hline 17 & B6 & 57,7 & 119,5 & 55,6 \\
\hline 18 & B7 & 63,5 & 69,0 & 51,6 \\
\hline 19 & B7 & 57,9 & 83,2 & 58,3 \\
\hline 20 & B7 & 54,9 & 79,4 & 61,0 \\
\hline 21 & B7 & 78,0 & 175,2 & 54,9 \\
\hline 22 & B8 & 56,8 & 114,3 & 45,5 \\
\hline 23 & B8 & 52,6 & 46,9 & 50,7 \\
\hline 24 & B4 & 52,7 & 89,0 & 54,9 \\
\hline 25 & B4 & 39,2 & 52,9 & 58,9 \\
\hline
\end{tabular}


LONGO, R. M.; FERREIRA, D. H. L.; SILVA, A. L.; PENEREIRO, J. C.; MENDES, D. R. Continuação

\begin{tabular}{|c|c|c|c|c|}
\hline 26 & B4 & 20,5 & 151,2 & 53,8 \\
\hline 27 & B4 & 58,4 & 125,9 & 58,1 \\
\hline 28 & B8 & 30,3 & 99,9 & 59,7 \\
\hline 29 & B8 & 16,7 & 48,1 & 57,2 \\
\hline 30 & B9 & 79,2 & 96,9 & 57,2 \\
\hline 31 & B9 & 31,1 & 102,9 & 54,4 \\
\hline 32 & B9 & 23,3 & 78,1 & 54,6 \\
\hline 33 & B9 & 28,5 & 46,3 & 56,1 \\
\hline 34 & $\mathrm{~B} 10$ & 13,4 & 101,4 & 58,6 \\
\hline 35 & B10 & 80,9 & 98,6 & 55,9 \\
\hline 36 & $\mathrm{~B} 10$ & 67,4 & 111,9 & 57,8 \\
\hline 37 & B2 & 23,7 & 133,9 & 57,8 \\
\hline 38 & $\mathrm{~B} 10$ & 27,9 & 110,7 & 53,1 \\
\hline 39 & B1 & 37,8 & 42,7 & 57,9 \\
\hline 40 & B1 & 5,6 & 128,4 & 56,1 \\
\hline \multicolumn{2}{|c|}{ Referência de Qualidade $^{1}$} & 13 & 17 & 40 \\
\hline \multicolumn{2}{|c|}{ Limite de Prevenção $^{1}$} & 30 & 72 & 75 \\
\hline \multicolumn{2}{|c|}{ nvestigação Agrícola Apmáx 1} & 70 & 180 & 150 \\
\hline
\end{tabular}

1 (CETESB, 2005). Valores Orientadores para Solos e Águas Subterrâneas no Estado de São

Fonte: Autores (2020). Paulo (Decisão de Diretoria $n^{\circ}$ 195-2005-E).

Uma comparação entre esses metais e os seus respectivos "Valores de Referência de Qualidade" (CETESB, 2005) encontram-se no histograma em forma de barras, representado na Figura 6, permitindo comparar o comportamento de cada metal pesado ao longo das bordas avaliadas na Mata de Santa Genebra. De forma geral, observa-se que as maiores concentrações médias dos metais pesados $\mathrm{Ni}, \mathrm{Pb}$ e $\mathrm{Cr}$ ocorreram nas bordas $\mathrm{B} 1, \mathrm{~B} 2$, B5, B6 e B9 (Figura 5). Essas bordas são referentes às regiões identificadas como intervenção: Urbana (B1), Outros cultivos (B2) e a Cana-de-açúcar (B5, B6 e B9).

Nas bordas próximas a área de Cana-de-açúcar (B5, B6 e B9) foram encontradas as maiores concentrações de tais metais, pressupõe-se que o uso de defensivos agrícolas e fertilizantes possam estar causando o aumento dessas substâncias no solo, devido a topografia e lixiviação natural desses compostos. Não se deve descartar ainda a hipótese de uma possível deposição pelo ar de partículas de substâncias químicas advindas das rodovias no entorno da Mata de Santa Genebra. No entanto, o maior destaque nesse estudo, advém da alta concentração na borda de Intervenção Urbana (B1), que possui a maior concentração de chumbo, sendo necessário avaliar sua fonte de emissão. 
LONGO, R. M.; FERREIRA, D. H. L.; SILVA, A. L.; PENEREIRO, J. C.; MENDES, D. R.

Atributos químicos e metais pesados em solos de remanescentes florestais urbanos

Figura 6: Histograma da distribuição dos metais nas bordas da Mata de Santa Genebra

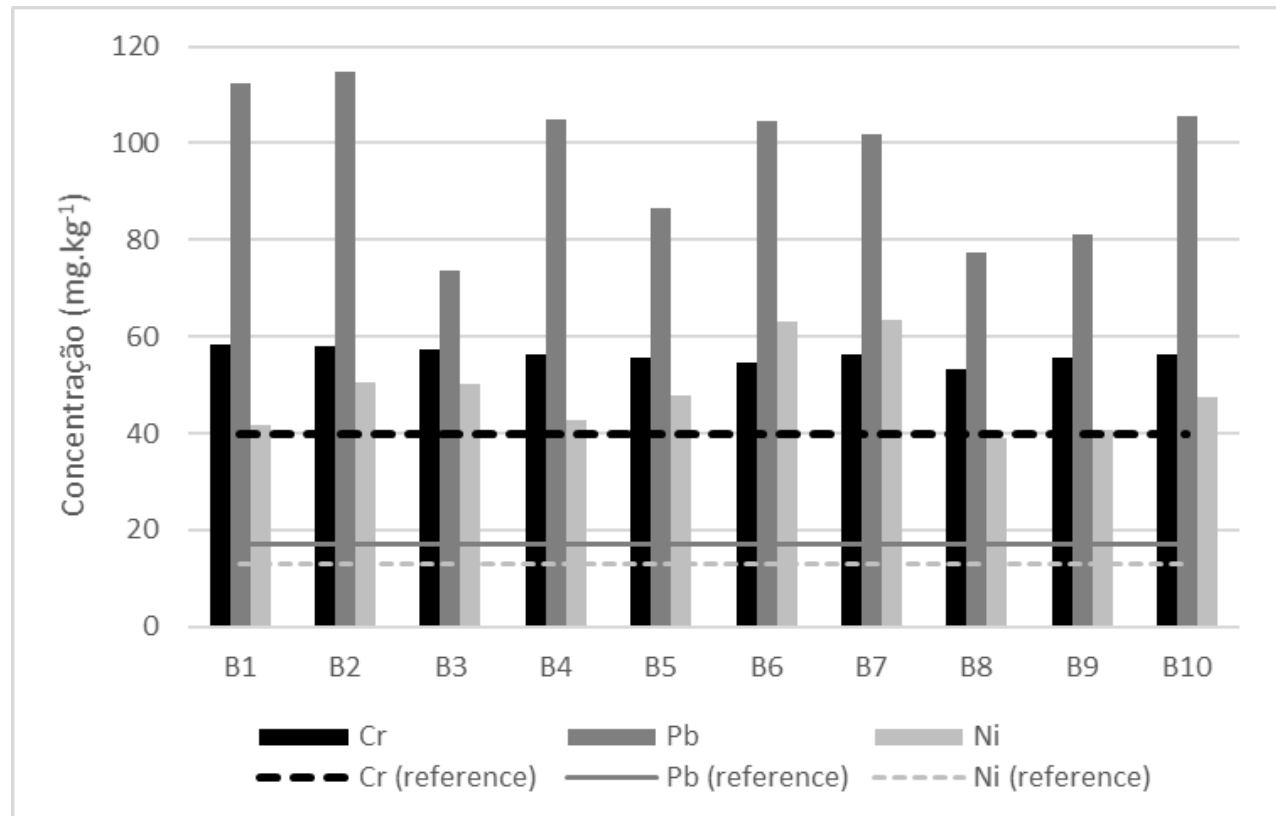

Fonte: Autores (2020).

Não se pode descartar a possibilidade da presença de metais pesados nos solos pela composição de origem natural, que, neste caso, depende do material de origem e do grau de intemperização que esse material sofreu. Por conta disso, percebe-se que o componente de origem antropogênica também é relevante, e presume-se que seja a principal razão do aumento crescente na concentração de metais pesados em solos agrícolas (ABREU et. al., 2002). Dos três metais trabalhados nessas análises, foi o $\mathrm{Pb}$ que se revelou como o mais contaminador, sendo, consequentemente, o que acusou as maiores intensidades nas dez bordas trabalhadas, conforme pode-se observar pelo Índice de Carga de Poluição (PLI) apresentado na Figura 7.

Os resultados revelaram que, no caso dos metais pesados analisados, o elemento $\mathrm{Cr}$ manteve-se estável ao longo das bordas, enquanto o $\mathrm{Ni}$ e $\mathrm{Pb}$ sofreram variações de concentrações elevadas, evidenciadas pelos valores superiores a $100\left(\mathrm{mg}_{\mathrm{gg}} \mathrm{kg}^{-1}\right)$ e, em pontos que possuem grande presença de árvores do tipo bambus e trepadeiras, no sub-bosque de árvores altas de troncos finos e ainda nas regiões de transição de tipos de borda, demostrando o efeito do ecótono. Com relação à mobilidade dos metais pesados, de acordo com Oliveira e Mattiazzo (2001), esta varia dependendo das reações de adsorção/dessorção, precipitação/dissolução, complexação e oxirredução. 
LONGO, R. M.; FERREIRA, D. H. L.; SILVA, A. L.; PENEREIRO, J. C.; MENDES, D. R. Atributos químicos e metais pesados em solos de remanescentes florestais urbanos

Figura 7: Índice de Carga de Poluição (PLI) nas áreas de borda da Mata de Santa Genebra

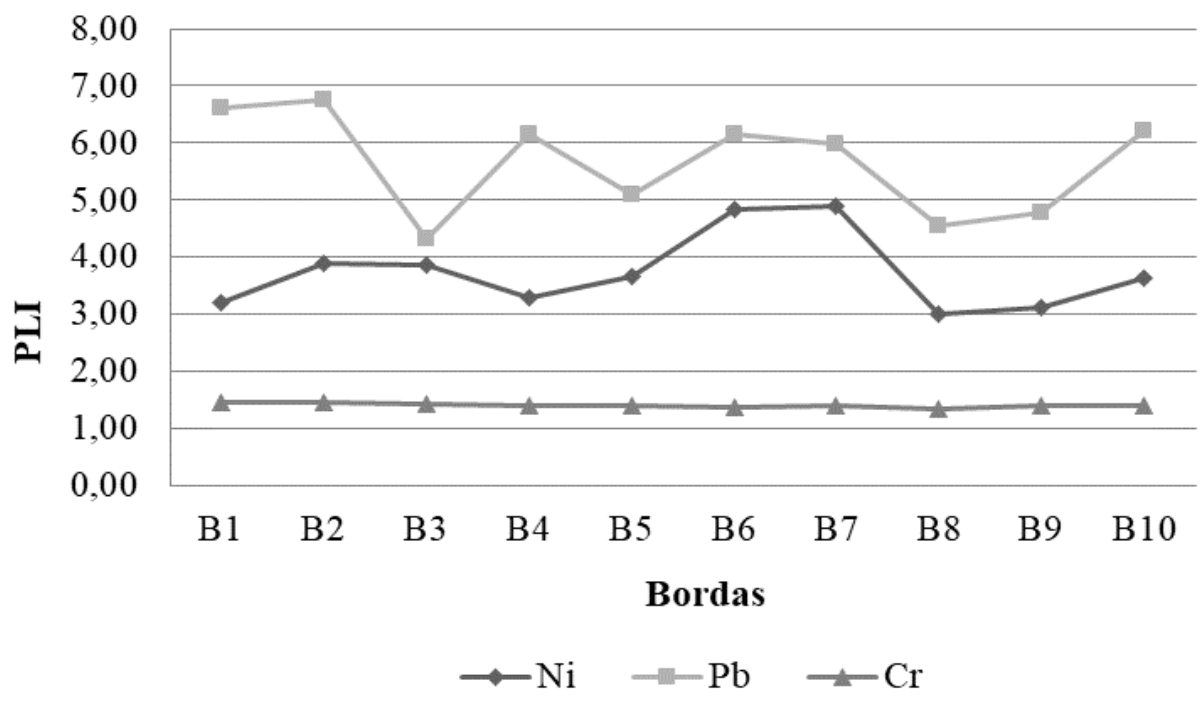

Fonte: Autores (2020)

Estas reações estão associadas aos atributos do solo, tais como teor de argila e matéria orgânica, $\mathrm{pH}$ e capacidade de troca de cátions que atuam influenciando. Em geral, quanto mais alto o conteúdo de argila, maior é a troca catiônica (em qualquer valor de $\mathrm{pH}$ ) e menor a mobilidade do metal no solo e, portanto, deduz-se que a contaminação de metais pesados neste perfil pode ter comportamento de mobilidade alta nos primeiros centímetros de profundidade (TAVARES et al., 2013). Logo, pode-se inferir que a mobilidade dos metais pesados na maioria dos solos diminui com o aumento do $\mathrm{pH}$ para valores próximos à neutralidade, em virtude da precipitação de formas insolúveis, como hidróxidos, carbonatos e complexos orgânicos. Para o solo em estudo foi observado que o $\mathrm{pH}$ ficou na faixa da neutralidade para alcalinidade.

Assim, segundo os limites impostos pela CETESB em sua normalização para os metais pesados (CETESB, 2005), o elemento Cr não necessita de adequação por estar na faixa de prevenção, o que é adequado para uma área de preservação. No entanto, os demais elementos nos pontos superiores a $30\left(\mathrm{mg}^{\mathrm{kg}}{ }^{-1}\right)$, no caso do $\mathrm{Ni}$, e $72\left(\mathrm{mg} \cdot \mathrm{kg}^{-1}\right)$, no caso do $\mathrm{Pb}$, necessitam de intervenção visando a diminuição de seus teores e adequação frente à legislação brasileira (CETESB, 2005). Neste caso, identificou-se que as maiores concentrações dos metais pesados $\mathrm{Ni}, \mathrm{Pb}$ e $\mathrm{Cr}$, em conjunto, ocorreram nas bordas $\mathrm{B} 5$ e $\mathrm{B} 6$, referentes às áreas de Intervenção: "Cana de açúcar 1 e 2", enquanto que para o elemento $\mathrm{Pb}$ a elevação foi inferida nas bordas B1 e B2, referentes às áreas de Intervenção: "Urbana" e "Outros cultivos", 
LONGO, R. M.; FERREIRA, D. H. L.; SILVA, A. L.; PENEREIRO, J. C.; MENDES, D. R.

Atributos químicos e metais pesados em solos de remanescentes florestais urbanos

neste último caso referindo-se às plantações de milho e banana. De acordo com Khan et al. (2008), a irrigação com águas residuais a longo prazo levou à contaminação de solos e culturas alimentares nas áreas de estudo. Metais pesados mostraram um acúmulo substancial implicando no aumento significativo sobre solos de referência. Além disso, os valores do índice de carga de poluição indicam que os solos, irrigados com águas residuais, foram moderadamente enriquecidos com $\mathrm{Cr}, \mathrm{Cu}, \mathrm{Ni}, \mathrm{Pb}$ e $\mathrm{Zn}$, porém foram fortemente enriquecidos com Cd.

Com base nos resultados obtidos pela análise dos componentes principais, aplicada aos dados de fertilidade e metais pesados, os respectivos autovalores e porcentagens da variância explicada por cada um estão apresentados na Tabela 3. Essa análise expressa a relação entre fatores e variáveis e permitem identificar aquelas com mais interrelações em cada componente (MENEZES et al., 2016). Desta forma, foi possível gerar componentes como resultado da combinação linear das 20 variáveis avaliadas no presente estudo. Observase pela Tabela 3 que as quatro primeiras componentes $(\mathrm{C} 1, \mathrm{C} 2, \mathrm{C} 3$ e $\mathrm{C} 4)$ explicam juntas $71,86 \%$ da variância total dos parâmetros avaliados, a partir da componente $\mathrm{C} 4$, as contribuições não foram mais tão significativas quando comparadas às primeiras.

Tabela 3: Autovalores da Matriz de Correlação dos parâmetros analisados

\begin{tabular}{|c|c|c|c|c|}
\hline Componente & Autovalores & Diferença & Proporção & $\begin{array}{c}\text { Proporção } \\
\text { Acumulada }\end{array}$ \\
\hline $\mathrm{C1}$ & 9,0843 & 6,7849 & 0,4542 & 0,4542 \\
\hline $\mathrm{C2}$ & 2,2994 & 0,6995 & 0,1150 & 0,5692 \\
\hline $\mathrm{C3}$ & 1,5998 & 0,2104 & 0,0800 & 0,6492 \\
\hline $\mathrm{C4}$ & 1,3895 & 0,2125 & 0,0695 & 0,7186 \\
\hline $\mathrm{C5}$ & 1,1769 & 0,1673 & 0,0588 & 0,7775 \\
\hline C6 & 1,0096 & 0,1693 & 0,0505 & 0,8280 \\
\hline C7 & 0,8403 & 0,1993 & 0,0420 & 0,8700 \\
\hline $\mathrm{C8}$ & 0,6409 & 0,1133 & 0,0320 & 0,9020 \\
\hline C9 & 0,5277 & 0,1410 & 0,0264 & 0,9284 \\
\hline C10 & 0,3867 & 0,0929 & 0,0193 & 0,9478 \\
\hline C11 & 0,2938 & 0,0996 & 0,0147 & 0,9624 \\
\hline $\mathrm{C12}$ & 0,1942 & 0,0275 & 0,0097 & 0,9722 \\
\hline $\mathbf{C 1 3}$ & 0,1666 & 0,0130 & 0,0083 & 0,9805 \\
\hline C14 & 0,1536 & 0,0439 & 0,0077 & 0,9882 \\
\hline C15 & 0,1098 & 0,0321 & 0,0055 & 0,9937 \\
\hline C16 & 0,0777 & 0,0351 & 0,0039 & 0,9975 \\
\hline $\mathrm{C17}$ & 0,0426 & 0,0361 & 0,0021 & 0,9997 \\
\hline C18 & 0,0066 & 0,0066 & 0,0003 & 1,0000 \\
\hline
\end{tabular}

Fonte: Autores (2020). 
LONGO, R. M.; FERREIRA, D. H. L.; SILVA, A. L.; PENEREIRO, J. C.; MENDES, D. R.

Atributos químicos e metais pesados em solos de remanescentes florestais urbanos

Os gráficos apresentados na Figura 8 evidenciam a associação direta entre as variáveis $\mathrm{SB}$ (somas das bases), $\mathrm{Ca}, \mathrm{pH}$ e $\mathrm{V}$, e CTC, $\mathrm{Mg}$ e $\mathrm{B}$, especialmente na Componente 1 onde os fatores ficaram entre 0,80 e 1,00; estas mesmas variáveis são inversamente proporcionais às variáveis $\mathrm{A}, \mathrm{H}+\mathrm{Al}$, e $\mathrm{Fe}$, cujos fatores ficam próximos a $-0,75$ e $-0,80$. Situação semelhante foi verificada por Islabão et al. (2013), que ao analisarem as propriedades químicas do solo de um campo de produção agrícola no Rio Grande do Sul, comprovaram um valor igual a $-0,70$ para a correlação da variável "concentração de alumínio", ou seja, valor semelhante ao observado no presente estudo para as variáveis $\mathrm{Al}$ e $\mathrm{H}+\mathrm{Al}$. De acordo com esta característica, os referidos autores identificaram que tal componente pode ser, portanto, interpretada como uma resposta relacionada à acidez e à calagem do solo. Entretanto, a maior acidez no solo conduz a maiores teores de Al, enquanto menores índices de $\mathrm{Ca}, \mathrm{Mg}$ e $\mathrm{K}$ diminui a soma das bases (SB) e aumenta a saturação de $\mathrm{Al}$. Por sua vez, as correlações entre $\mathrm{Ca}$ e $\mathrm{Mg}$ e $\mathrm{V}, \mathrm{pH}$ e CTC indicam um efeito de calagem no solo.

Pode-se considerar, portanto, que $\mathrm{C} 1$ representa uma componente natural, o que se justifica pela predominância natural de $\mathrm{Fe}$ em solos tropicais, que está também associado à umidade e teor de matéria orgânica. Além disso, como já discutido, é comum que solos de florestas tropicais apresentem maior acidez; no presente estudo, esta maior acidez potencial (menor $\mathrm{pH}$ ) esteve associada também aos menores teores de bases como $\mathrm{Ca}^{2+}$.

Por sua vez, as demais componentes, que incluem os elementos $\mathrm{Cu}, \mathrm{Cr}, \mathrm{Pb}, \mathrm{Ni}$ e $\mathrm{Zn}$, podem ser consideradas como componentes antropogênicas, de forma semelhante a identificada por Moura, Moita e Neto (2010). De fato, os resultados das análises químicas do solo evidenciaram que os maiores teores de metais pesados estiverem associados aos pontos de coleta na interface entre a mata e as áreas urbanas e de cultivo de cana-de-açúcar, na qual pressupõe que fertilizantes e outros defensivos possam contribuir para a maior concentração destas substâncias. 
LONGO, R. M.; FERREIRA, D. H. L.; SILVA, A. L.; PENEREIRO, J. C.; MENDES, D. R.

Atributos químicos e metais pesados em solos de remanescentes florestais urbanos

Figura 8: Comportamento dos principais índices químicos e metais pesados existentes entre C1, C2, C3 e C4 na Mata de Santa Genebra

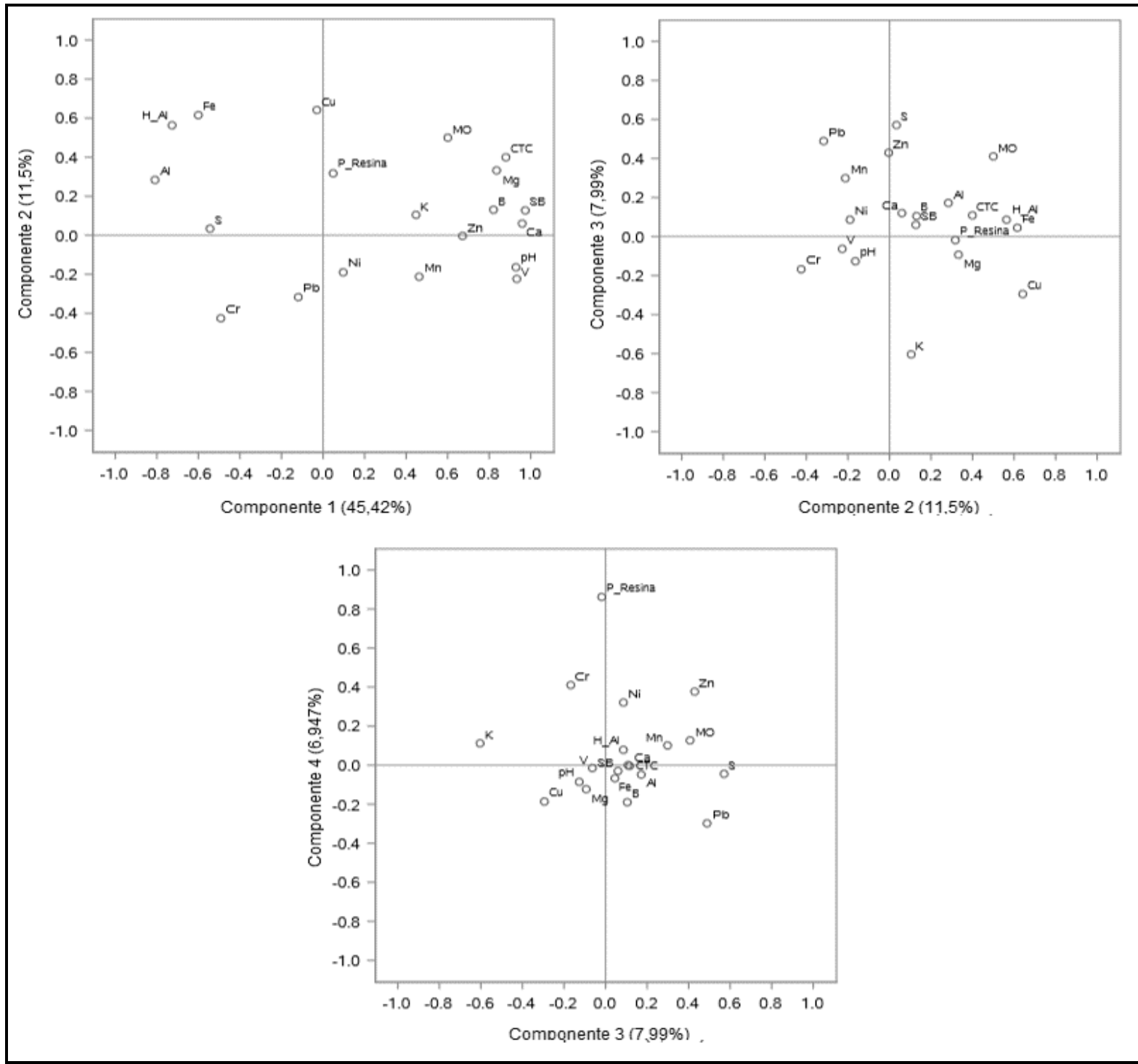

Fonte: Autores (2020).

\section{CONCLUSÕES}

De maneira geral, os resultados apresentados neste trabalho permitiram concluir que:

$\checkmark$ O remanescente florestal Mata de Santa Genebra encontra-se em boas condições de conservação em relação à fertilidade do solo, o que pode vir a auxiliar nos programas de reflorestamento. 
LONGO, R. M.; FERREIRA, D. H. L.; SILVA, A. L.; PENEREIRO, J. C.; MENDES, D. R.

Atributos químicos e metais pesados em solos de remanescentes florestais urbanos

No entanto, algumas regiões principalmente aquelas que se encontram sob pressões externas (urbanização, presença de estradas e atividades rurais), acentuam o denominado "efeito de borda" referentes aos parâmetros de solo analisados.

$\checkmark$ De um modo geral, identificou-se que as maiores concentrações dos metais pesados $\mathrm{Ni}, \mathrm{Pb}$ e $\mathrm{Cr}$, em conjunto, ocorreram nas bordas $\mathrm{B} 5 \mathrm{e} \mathrm{B} 6$, referentes às áreas de intervenção: "Cana de açúcar 1 e 2", enquanto que para o elemento $\mathrm{Pb}$ a elevação foi inferida nas bordas B1 e B2, referentes às áreas de intervenção: "Urbana" e "Outros cultivos".

$\checkmark$ Embora as análises realizadas demonstrem correlação entre a presença de metais pesados e a qualidade química, estes não podem ser considerados os únicos fatores de distúrbio do solo nas bordas do remanescente, necessitando assim de um estudo mais abrangente para a determinação de indicadores de degradação e a caracterização da borda aqui tratada.

De modo geral, pode-se observar que realização de análises químicas no solo e sua interpretação visando a tomada de decisão é uma ação de fundamental importância, não só para o conhecimento dos fenômenos presentes na região de interesse, mas também como fator orientador para a implantação de projetos que visem recuperar, ou remediar áreas que foram degradadas.

\section{AGRADECIMENTOS}

À Fundação de Apoio à Pesquisa do Estado de São Paulo (FAPESP) pelo apoio financeiro (processo no 2018/17250-3); à Coordenação de Aperfeiçoamento de Pessoal de Nível Superior - Brasil (CAPES) - Código de Financiamento 001 pela bolsa de mestrado e a FAPIC/Reitoria da PUC-Campinas pela concessão da bolsa de iniciação científica.

\section{REFERÊNCIAS}

ABREU, C. A.; ABREU, M. F.; BERTON, R. S. Análise química de solo para metais pesados. In: Sociedade Brasileira de Ciência do Solo. Tópicos em Ciência do Solo, v. 2, p. 645-692, 2002.

ALEXANDRE, J. R. et al. Zinco e ferro: de micronutrientes a contaminantes do solo. Natureza on line, v. 10, n. 1, p. 23-28, 2012.

BIONDI, C. M. Teores naturais de metais pesados nos solos de referência do estado de pernambuco. [s.1.] Universidade Federal Rural de Pernambuco, 2010. 
LONGO, R. M.; FERREIRA, D. H. L.; SILVA, A. L.; PENEREIRO, J. C.; MENDES, D. R. Atributos químicos e metais pesados em solos de remanescentes florestais urbanos

CETESB. Companhia de Tecnologia de Saneamento Ambiental. Dispõe sobre a aprovação dos Valores Orientadores para Solos e Águas Subterrâneas no Estado de São Paulo 2005, em substituição aos Valores Orientadores de 2001, e dá outras providências. Decisão de Diretoria n ${ }^{\circ} 195-2005-E$, de 23 de novembro de 2005.

ETTO, T. L.; LONGO, R. M.; ARRUDA, D. R.; INVENIONI, R. Ecologia da paisagem de remanescentes florestais na bacia hidrográfica do Ribeirão das Pedras - Campinas-SP. Revista Árvore, v. 37, n. 6, p. 1063-1071, 2013.

FENGLER, F. H.; MORAES, J. F. L.; RIBEIRO, A. I.; FILHO, A. P.; STORINO, M.; MEDEIROS, G. A. Qualidade ambiental dos fragmentos florestais na Bacia Hidrográfica do Rio Jundiaí-Mirim entre 1972 e 2013. Revista Brasileira de Engenharia Agrícola e Ambiental, v. 19, n. 4, p. 402-408, 2015.

FERREIRA, A. P. Distribution and contamination of metals in the soil of Guandu Watershed. Ambiente e Água, v. 10, n. 4, p. 758-769, 2015.

FERREIRA, A. P.; HORTA, M. A. P. Trace element in water, sediments, and organs of Savacu (Nycticorax nyctiorax) from Sepetiba Bay, Rio de Janeiro, Brazil. Ambiente e Água, v. 5, n. 1, p. 17-28, 2010.

GARCIA, J. M.; LONGO, R. M.; PENEREIRO, J. C.; MENDES, D. R.; MANTOVANI, P. Uso de fotografias hemisféricas para avaliação da qualidade ambiental na Mata de Santa Genebra, Campinas-SP, Brasil. Ciência Florestal, v. 18, n.1, p. 175-190, 2018.

GREGGIO, T. C.; PISSARRA, T. C. T.; RODRIGUES, F. M. Avaliação dos fragmentos florestais do município de Jaboticabal, SP. Revista Árvore, v. 33, n. 1, p. 117-124, 2009.

INDA, A. V.; TOMASI, C. A.; OLIVEIRA, J. S.; FINK, J. R. Óxidos de ferro e área superficial de Latossolo subtropical sob campo e floresta nativa. Ciência Rural, v. 44, n. 2, p. 289-292, 2014.

INDA, A. V.; TORRENT, J.; BARRÓN, V.; BAYER, C.; FINK, J. R. Iron oxides dynamics in a subtropical Brazilian Paleudult under long-term no-tillage management. Scientia Agricola, v. 70, n. 1, p. 48-54, 2013.

ISLABÃO, G. O.; PINTO, M. A. B.; SELAU, L. P. R.; VAHL, L. C.; TIM, L. C. Caracterization of soil chemical properties of strawberry fields using principal components analysis. Revista Brasileira de Ciência do Solo, v. 37, n. 1, p. 168-176, 2013.

KHAN, S.; CAO, Q.; ZHENG, Y. M.; HUANG, Y. Z.; ZHU, Y. G. Health risks of heavy metals in contaminated soils and food crops irrigated with wastewater in Beijing, China. Environmental Pollution, v. 152, p. 686-692, 2008.

LIU, W. H.; ZHAO, J. Z.; OUYANG, Z. Y.; SODERLUND, L.; LIU, G. H. Impacts of sewage irrigation on heavy metals distribution and contamination in Beijing, China.

Environment International, v. 31, p. 805-812, 2005. 
LONGO, R. M.; FERREIRA, D. H. L.; SILVA, A. L.; PENEREIRO, J. C.; MENDES, D. R. Atributos químicos e metais pesados em solos de remanescentes florestais urbanos

LONGO, R. M.; MULATO, A. L.; MISONO, T. A. M.; SILVA, M. F.; DEMAMBORO, A. C.; BETTINE, S. C.; RIBEIRO, A. I. Environmental impact assessment of the surrounding areas of urban forests. WIT Transactions on Ecology and the Environment, v. 193, p. 501$508,2015$.

LONGO, R. M.; ZANGIROLAMI, G. F.; YAMAGUCHI, C. S.; DEMAMBORO, A. C.; BETTINE, S. C.; RIBEIRO, A. I. Impacts of agricultural activities in remaining forest: Campinas/SP, Brazil. WIT Transactions on Ecology and the Environment, v. 170, p. 1523, 2013.

MENEZES, J. P. C; BITTENCOURT, R. P.; FARIAS, M. S.; BELLO, I. P.; FIA, R.; OLIVEIRA, L. F. C. Relação entre padrões de uso e ocupação do solo e qualidade da água em uma bacia hidrográfica urbana. Revista Engenharia Sanitária e Ambiental, v. 21, n. 3, p. 519-534, 2016.

MORELLATO, P. C.; LEITÃO-FILHO, H. F. Ecologia e preservação de uma floresta tropical urbana: Reserva de Santa Genebra, São Paulo, 1995. Ed. da UNICAMP, 1995.

MOURA, M. C. S.; MOITA, G. C.; NETO, J. M. M. Analysis and assessment of heavy metals in urban surface soils of Teresina, Piauí State, Brazil: a study based on multivariate analysis. Comunicata Scientiae, v. 1, n. 2, p. 120-127, 2010.

OLIVEIRA, F. C., MATTIAZO, M. E. Mobilidade de metais pesados em um Latossolo amarelo distrófico tratado com lodo de esgoto e cultivado com cana-de-açucar. Scientia Agricola, v. 58, n. 4, p. 807-812, 2001.

OLIVEIRA, L. S. C.; MARANGON, L. C.; FELICIANO, A. L. P.; LIMA, A. S.; CARDOSO, M. S. O.; SANTOS, W. B. Efeito de borda em remanescentes de Floresta Atlântica na Bacia do Rio Tapacurá, Pernambuco. CERNE, v. 21, n. 2, p. 169-174, 2015.

RAIJ, B. V.; QUAGGIO, J. A.; CANTARALLA, H. Análise química do solo para fins de fertilidade. Campinas: Fundação Cargill, 1987. 170 p.

SANTOS, A. L. C; CARVALHO, C. M.; CARVALHO, T. M. Importância de remanescentes florestais para conservação da biodiversidade: Estudo de caso na Mata Atlântica em Sergipe através de sensoriamento remoto. Revista Geográfica Acadêmica, v. 7, n. 2, p. 58-84, 2013.

SANTOS, R. S.; BARRETO-GARCIA, P. A. B.; SCORIZA, R. N. Fungos micorrízicos arbusculares e serapilheira como indicadores do efeito de borda em fragmento de floresta estacional. Ciência Florestal, v. 28, n. 1, p. 324-335, 2018.

SANTOS, R. D. DOS et al. Manual de Descrição e Coleta de Solo no Campo. $5^{\text {a }}$ ed. Viçosa: Sociedade Brasileira de Ciência do Solo, 2005.

SILVA, F. A. S.; AZEVEDO, C. A. V. The Assistat Software Version 7.7.and its use in the analysis of experimental data. African Journal Agricultural Research, v. 11, n.39, p. 37333740, 2016. 
LONGO, R. M.; FERREIRA, D. H. L.; SILVA, A. L.; PENEREIRO, J. C.; MENDES, D. R. Atributos químicos e metais pesados em solos de remanescentes florestais urbanos

SILVA, G. F. Indicadores de qualidade do solo sob diferentes sistemas de uso na mesorregião do agreste paraibano. Revista Caatinga, v. 28, n. 3, p. 25-35, 2015.

SILVA, K. G.; SANTOS, A. R.; SILVA, A. G.; PELUZIO, J. B. E.; FIEDLER, N. C.; ZANETTI, S. S. Análise da dinâmica espaço-temporal dos fragmentos florestais da sub-bacia hidrográfica do Rio Alegre, ES. CERNE, v. 21, n. 2, p. 311-318, 2015.

SOFFINIAN, A.; MADANI, E. S.; ARABI, M. Risk assessment of heavy metal soil pollution through principal componentes analysis and false color composition in Hamadan Province, Iran. Environmental Systems Research, v. 3, n. 3, p. 1-14, 2014.

SOUZA JUNIOR, I. G.; COSTA, A. C. S.; VILAR, C. C.; HOEPERS, A. Mineralogia e susceptibilidade magnética dos óxidos de ferro do horizonte B de solos do Estado do Paraná. Ciência Rural, v. 40, n. 3, p. 513-519, 2010.

TAVARES, S. R. L.; OLIVEIRA, A. S.; SALGADO, C. M. Avaliação de espécies vegetais na fitoremediação de solos contaminados por metais pesados. Holos, v. 29, n. 5, p. 80-97, 2013.

TSUTIYA, M. T. Metais pesados: o principal fator limitante para o uso agrícola de biossólidos das estações de tratamento de esgotos. Engenharia Sanitária e Ambiental, v. 140, p. 753-761, 2015.

USEPA. US. Environmetal Protection Agency - Usepa. 3050B: Acid Digestion of Sediments, Sludges, and Soils. Physical/Chemical Methods: Office of Solid Waste, U.S. Environmental Protection Agency. Washington, 1996.

VELOSO, H. P.; RANGEL FILHO, A. L. R.; LIMA, J. C. A. Classificação da Vegetação Brasileira Adaptada a um Sistema Universal. Rio de Janeiro, Editor: IBGE, 1991, 123p.

YADA, M. M.; MINGOTTE, F. L. C.; MELO, W. J.; MELO, G. P.; MELO, V. P.; LONGO, R. M.; RIBEIRO, A. I. Atributos Químicos e Bioquímicos em Solos Degradados por Mineração de Estanho e em Fase de Recuperação em Ecossistema Amazônico. Revista Brasileira Ciência do Solo, v. 39, p. 714-724, 2015.

\section{Autores}

Regina Márcia Longo - É Graduada em Agronomia pela Universidade Estadual Paulista "Júlio de Mesquita Filho" (UNESP); Mestra e Doutora em Engenharia Agrícola pela Universidade Estadual de Campinas (UNICAMP). Atualmente é Professora do Programa de Pós-Graduação em Sustentabilidade e em Infraestrutura Urbana da Pontifícia Universidade Católica de Campinas (PUC-Campinas). 
LONGO, R. M.; FERREIRA, D. H. L.; SILVA, A. L.; PENEREIRO, J. C.; MENDES, D. R. Atributos químicos e metais pesados em solos de remanescentes florestais urbanos

Denise Helena Lombardo Ferreira - É Graduada em Matemática pela Universidade Estadual Paulista "Júlio de Mesquita Filho" (UNESP) e em Tecnologia em Saneamento pela Universidade Estadual de Campinas (UNICAMP); Mestra em Matemática Aplicada pela Universidade Estadual de Campinas (UNICAMP) e Doutora em Educação Matemática pela Universidade Estadual Paulista "Júlio de Mesquita Filho" (UNESP). Atualmente é Professora do Programa de Pós-Graduação em Sustentabilidade da Pontifícia Universidade Católica de Campinas (PUC-Campinas).

Alessandra Leite da Silva - É Graduada em Engenheira Ambiental e Sanitária e Mestra em Sistemas de Infraestrutura Urbana pela Pontifícia Universidade Católica de Campinas (PUCCampinas). Doutoranda em Ciências Ambientais pela Universidade Estadual Paulista "Júlio de Mesquita Filho" (UNESP/campus Sorocaba).

Júlio César Penereiro - É Graduado em Física pela Universidade Estadual de Campinas (UNICAMP); Mestre e Doutor em Astronomia pela Universidade Estadual de São Paulo (USP). Atualmente atua no Observatório Municipal de Campinas Jean Nicolini.

Deborah Regina Mendes - É Graduada em Engenheira Ambiental e Sanitária pela Pontifícia Universidade Católica de Campinas (PUC-Campinas).

Artigo recebido em: 02 de março de 2020.

Artigo aceito em: 14 de setembro de 2020. Artigo publicado em: 21 de setembro de 2020. 